\title{
Amino-Nogo-A antagonizes reactive oxygen species generation and protects immature primary cortical neurons from oxidative toxicity
}

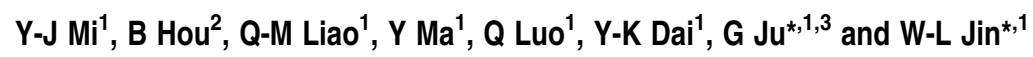

Nogo-A is originally identified as an inhibitor of axon regeneration from the CNS myelin. Nogo-A is mainly expressed by oligodendrocytes, and also by some neuronal subpopulations, particularly in the developing nervous system. Although extensive studies have uncovered regulatory roles of Nogo-A in neurite outgrowth inhibition, precursor migration, neuronal homeostasis, plasticity and neurodegeneration, its cell-autonomous functions in neurons are largely uncharacterized. Here, we show that HIV-1 trans-activating-mediated amino-Nogo-A protein transduction into cultured primary cortical neurons achieves an almost complete neuroprotection against oxidative stress induced by exogenous hydrogen peroxide $\left(\mathrm{H}_{2} \mathrm{O}_{2}\right)$. Endogenously expressed neuronal Nogo-A is significantly downregulated upon $\mathrm{H}_{2} \mathrm{O}_{2}$ treatment. Furthermore, knockdown of Nogo-A results in more susceptibility to acute oxidative insults and markedly increases neuronal death. Interacting with peroxiredoxin 2 (Prdx2), amino-Nogo-A reduces reactive oxygen species (ROS) generation and extracellular signal-regulated kinase phosphorylation to exert neuroprotective effects. Structure-function mapping experiments reveal that, out of $\mathrm{NiG}-\Delta 20$, a novel region comprising residues 290-562 of amino-Nogo-A is indispensable for preventing oxidative neuronal death. Moreover, mutagenesis analysis confirms that cysteine residues 424, 464 and 559 are involved in the inhibition of ROS generation and neuroprotective role of amino-Nogo-A. Our data suggest that neuronal Nogo-A might play a cell-autonomous role in improving neuronal survival against oxidative insult through interacting with Prdx2 and scavenging of ROS.

Cell Death and Differentiation (2012) 19, 1175-1186; doi:10.1038/cdd.2011.206; published online 20 January 2012

Nogo-A has been intensively investigated as one of the most potent myelin-associated neurite growth inhibitors of the adult CNS during the past decade., 1 The nogo gene generates three major protein products, Nogo-A, $-B$ and $-C$, by both alternative promoter usage and splicing. All the three isoforms of Nogo share a 66-amino-acid (aa) residue extracellular domain (Nogo-66) and a C-terminal domain. Nogo-A and Nogo-B have a common unique acidic $\mathrm{N}$-terminal domain. The longest isoform (1192 aa in human), Nogo-A, contains a long Nogo-A-specific region (aa 186-1004) known as 'amino-Nogo-A'. At least three discrete regions have been proven to inhibit neurite outgrowth and cell spreading. ${ }^{1-3}$ Nogo-66 binds to a receptor complex containing $\mathrm{NgR}$, P75/TROY and LINGO-1, and activates the small Rho GTPase RhoA and ROCK., ${ }^{1,2}$ Two other regions, NiR- $\Delta 2$ (aa 57-185) and NiG- $\Delta 20$ (aa 564-749), are also found to be inhibitory for neurite outgrowth, ${ }^{3}$ the latter may depend on integrin signaling and pincher-mediated macroendocytosis. ${ }^{4,5}$

Besides mature oligodendrocytes, several subtypes of neurons express Nogo-A proteins, particularly in the developing nervous system. ${ }^{6-8}$ Unlike the well-known functions and signal pathways of oligodendrocyte-derived Nogo-A, ${ }^{1,2}$ the important features of neuronal Nogo-A are beginning to be understood. In the developing forebrain cortex, Nogo-A is expressed in radial glia cells, postmitotic neuronal precursors and cortical neurons. In mice lacking Nogo-A, radial and tangential migrations of neural precursors and interneurons are influenced in early cortical development and neuronal maturation. ${ }^{8}$ Cultured dorsal root ganglia (DRG) neurons from Nogo-A KO mice or Nogo-A antibodies neutralization experiments suggest that neuronal Nogo-A regulates neurite fasciculation, branching and extension. ${ }^{9}$ In the adult CNS, Nogo-A proteins are located at synapse and restrict synaptic plasticity $^{10}$ and stabilize the architecture of hippocampal neurons. ${ }^{11}$ To date, new findings of neuronal Nogo-A are logically in line with localization of Nogo-A and Nogo-66/NgRmediated signaling; however, concrete evidence for a direct role of amino-Nogo-A in the CNS is not yet available.

Some findings have also implicated neuronal Nogo in several neurodegenerative pathologies. ${ }^{12,13}$ For example,

\footnotetext{
${ }^{1}$ Institute of Neurosciences, School of Life Sciences and Biotechnology, Shanghai Jiao Tong University, Shanghai 200240, China; ${ }^{2}$ State Key Laboratory of Proteomics, Beijing Institute of Radiation Medicine, Beijing 100850, China and ${ }^{3}$ Institute of Neurosciences, The Fourth Military Medical University, X'an, Shaanxi 710032, China *Corresponding authors: G Ju, Institute of Neurosciences, The Fourth Military Medical University, Xi'an, Shaanxi 710032, China. Tel: + 86 29 84774558; Fax: + 8629 83246270; E-mail: jugong@fmmu.edu.cn

or W-L Jin, Institute of Neurosciences, School of Life Sciences and Biotechnology, Shanghai Jiao Tong University, Room 509, Wen Xuan Medical Building, 800 Dong Chuan Road, Minhang, Shanghai 200240, China. Tel: + 8621 34204287; Fax: + 8621 34204270; E-mail: weilinjin @yahoo.com or weilinjin @ sjtu.edu.cn Keywords: Nogo-A; ROS; neuroprotection; Prdx2; cortical neurons

Abbreviations: aa, amino acid; BIAM, biotin-conjugated iodoacetamide; CNS, central nervous system; Cys, cysteine; DHE, dihydroethidium; E, embryonic; ERK, extracellular signal-regulated kinase; P, postnatal; Prdx2, peroxiredoxin 2; ROS, reactive oxygen species; shRNA, small hairpin RNA; siRNA, small interfering RNA; TAT, HIV-1 trans-activating; Trx, thioredoxin

Received 20.6.11; revised 05.12.11; accepted 05.12.11; Edited by N Bazan; published online 20.1.12
} 
Nogo-A protein levels are markedly altered in hippocampal neurons of patients who suffered from Alzheimer disease (AD) and temporal lobe epilepsy (TLE), in the brain and muscle of patients with amyotrophic lateral sclerosis (ALS) and in schizophrenic patients. ${ }^{12,13}$ Oxidative stress is increasingly implicated as a pivotal underlying pathogenic mechanism in the onset and progression of the neurodegenerative diseases. ${ }^{14}$ Meanwhile, there is no solid evidence yet that alteration of Nogo levels observed in AD, TLE, ALS or schizophrenia has a direct role in disease progression; thus, it is of importance to check whether intracellular amino-Nogo-A is involved in oxidative stress using $\mathrm{H}_{2} \mathrm{O}_{2}$-induced cell death model. In this study, we find that neuronal Nogo-A may play a cell-autonomous survival role through its amino-Nogo-A. Designed to mimic the role of intracellular Nogo-A, HIV-1 trans-activating (TAT)-amino-Nogo-A has been shown to exert a strong pro-survival effect on cortical neurons undergoing oxidative stress. The actions are attributable to interaction of amino-Nogo-A with peroxiredoxins (Prdx2) and subsequent inhibition of reactive oxygen species (ROS) generation and downstream activation of extracellular signalregulated kinase (ERK) signaling pathway. Here, we report a unique intracellular function of the long amino-Nogo-A related to neuronal survival beyond its neurite growth inhibitory activity, and this finding may provide us new insights into the potential roles of Nogo-A for neurodegenerative diseases.

\section{Results}

Intracellular localization and topology of amino-Nogo-A in developing cortical neurons. To begin our study of the role of amino-Nogo-A in cortical neurons, we first examined its intracellular localization. Nogo-A was highly expressed in the developing cortical neurons (Figure $1 \mathrm{~b}$, top panel), and it localized to cytosolic (F1), organelle/membrane (F2), nucleic (F3) and cytoskeleton fractions (F4), with the majority residing in $\mathrm{F} 1$ and $\mathrm{F} 2$ (Figure $1 \mathrm{~b}$, lower panel). These data are consistent with previous studies. ${ }^{7,8}$

We then determined the membrane topology of aminoNogo-A in cortical neurons using living cell staining with A620, 1 E8 and A201 antibodies. ${ }^{15}$ The data indicate that amino-Nogo-A is present intracellularly in developing cortical neurons (Figure 1c).

Neuronal Nogo-A mRNA and protein are downregulated after $\mathrm{H}_{2} \mathrm{O}_{2}$ treatment. Neurons are particularly sensitive to $\mathrm{H}_{2} \mathrm{O}_{2}$, while astrocytes have a protective effect against
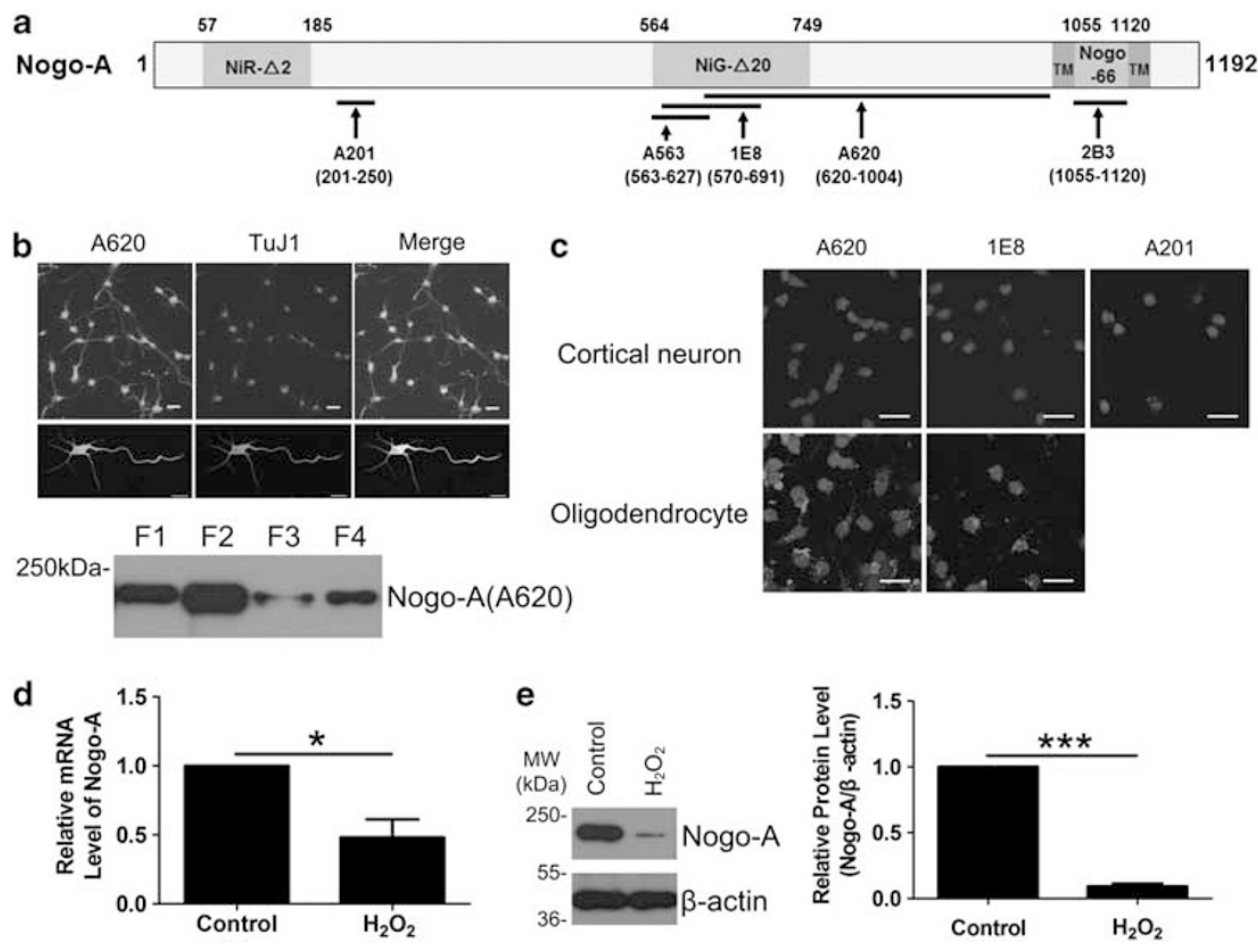

Figure 1 Nogo-A expression in cortical neurons. (a) The diagram for antibodies against different antigen recognition sites of human Nogo-A NiR- $\triangle 2$ (amino acids (aa) 57-185), NiG- $\Delta 20$ (aa 564-749) and Nogo-66 (aa 1055-1120) are the three inhibitory regions of human Nogo-A. TMs are transmembrane domains located on the two sides of Nogo-66. The arrows indicate the target regions of five Nogo-A-specific antibodies, polyclonal antibody (pAb) A201 against aa 201-250, monoclonal antibody (mAb) A563 against aa 563-627, mAb 1E8 against aa 570-691 and pAb A620 against aa 620-1004. 2B3 is targeted to Nogo-66, aa 1055-1120. (b) Top: the expression of neuronal Nogo-A was immunostained with A620 and TuJ1, an immature neuronal marker. Lower: subcellular distribution of neuronal Nogo-A was blotted with A620. Cytosolic (F1), organelle/membrane (F2), nucleic (F3) and cytoskeleton fractions (F4) were the four subcellular fractions of neurons. (c) Living cell staining for neurons were performed with pAb A620, mAb $1 E 8$ or pAb A201 (top). The A620 and 1E8 antibodies had previously been shown to label the extracellular amino-Nogo-A in oligodendrocytes (lower). (d) The total RNA was extracted from neurons exposed to $50 \mu \mathrm{M}$ hydrogen peroxide $\left(\mathrm{H}_{2} \mathrm{O}_{2}\right)$ for $8 \mathrm{~h}$ or not and submitted to quantitative real-time polymerase chain reaction (PCR). $\beta$-Actin was selected as an inner standard. (e) Cell lysates from neurons exposed to $50 \mu \mathrm{M} \mathrm{H}_{2} \mathrm{O}_{2}$ for $8 \mathrm{~h}$ or not were blotted with pAb A620. $\beta$-Actin was selected as an inner standard (left). Quantification by densitometric scans was presented by Nogo-A $/ \beta$-actin (right). Bar $=50 \mu \mathrm{m} . n=3$, mean $\pm \mathrm{S}$.D., paired $t$-test, ${ }^{*} P<0.05$, ${ }^{* \star *} P<0.001$ 
$\mathrm{H}_{2} \mathrm{O}_{2}$-induced neurotoxicity. Nearly purified primary cortical neurons (Supplementary Figure S1a) showed a $\mathrm{H}_{2} \mathrm{O}_{2}$ concentration-dependent decrease in cell viability, and $50 \mu \mathrm{M}$ of $\mathrm{H}_{2} \mathrm{O}_{2}$ for $12 \mathrm{~h}$ led to $50-60 \%$ cell death compared with control (Supplementary Figures $\mathrm{S} 1 \mathrm{~b}-\mathrm{d}$ ). The sublethal dose of $\mathrm{H}_{2} \mathrm{O}_{2}(50 \mu \mathrm{M})$ was applied for the following studies. Exposed to $\mathrm{H}_{2} \mathrm{O}_{2}$ for $8 \mathrm{~h}$, neuronal Nogo-A mRNA $(P<0.05)$ and protein levels $(P<0.001)$ decreased sharply compared with control (Figures $1 \mathrm{~d}$ and $\mathrm{e}$ ). In addition, the reduction of Nogo-A mRNA caused by $\mathrm{H}_{2} \mathrm{O}_{2}$ exhibited a time-dependent manner (Supplementary Figure S2).

TAT-amino-Nogo-A protects cortical neurons against $\mathrm{H}_{2} \mathrm{O}_{2}$-induced cell death. Next, we investigated the potential role of amino-Nogo-A in neuronal oxidative damage model induced by $\mathrm{H}_{2} \mathrm{O}_{2}$. The two differential $\mathrm{N}$ terminus of Nogo-A fusion proteins, TAT-AN and TAT-AM, were purified, transduced into neurons by TAT (Figures $2 \mathrm{a}$ and $b$ ) and sustained as stable for at least $14 \mathrm{~h}$ (data not shown).

We then tested the effects of transduced TAT-AN and TAT-AM on cell viability. Propidium iodide (PI)/Hoechst staining (Figures 2c and d) and 3-(4,5-dimethyldiazol-2-yl)2,5-diphenyltetrazolium bromide (MTT) assay (Figure 2e) showed that both TAT-AN and TAT-AM significantly prevented neurons from $\mathrm{H}_{2} \mathrm{O}_{2}$, and this effect was nearly comparable to control $(P<0.001)$. The control protein, TAT-GFP, showed no protection (Figures $2 \mathrm{c}-\mathrm{e}$ ).

Meanwhile, another control noTAT-AM protein with the removal of TAT protein transduction domain had a poor transducible ability and weak neuroprotective effect in cortical neurons (Supplementary Figures S3a and b), in which may be the presence of an unknown receptor for NiG- $\Delta 20 .^{3,5}$ Another recombinant glutathione $S$-transferase (GST)-AM was used to exclude the possibility that amino-Nogo-A could reduce $\mathrm{H}_{2} \mathrm{O}_{2}$ outside of cells; GST-AM showed neurite outgrowth inhibitory activity as a substrate (Supplementary Figure S4a). No significant protection was demonstrated by cell death assay (Supplementary Figure S4b).

We further tested dose- and time-dependency of TAT-amino-Nogo-A for neuroprotective effect. Pretreatment with TAT-AM at $0.02 \mu \mathrm{M}$ or more gradually reduced cell death induced by $\mathrm{H}_{2} \mathrm{O}_{2}$, and the effects reached peak at $0.2 \mu \mathrm{M}$ (Figure 2f), and thus we selected $0.2 \mu \mathrm{M}$ as the appropriate working dose. In the time-dependency examination, we found that pretreatment or co-treatment of amino-Nogo-A could exert the equivalent and completely protective effect and posttreatment after 5 min of $\mathrm{H}_{2} \mathrm{O}_{2}$ exposure still retained a strong protection, but after $30 \mathrm{~min}$ it did not provide benefit (Figure $2 \mathrm{~g}$ ). Taken together, these data indicate that aminoNogo, especially the long middle region unique to Nogo-A, strongly increases neuronal resistance to oxidative stress and the action exhibits dose- and time-dependent manners.

Suppression of Nogo-A increases neuronal susceptibility to $\mathrm{H}_{2} \mathrm{O}_{2}$. To exploit if endogenous Nogo-A is involved in oxidative stress resistance, we knockdown its expression by one small interfering RNA (siRNA) and two small hairpin RNA (shRNA) constructs. To visualize the effect of transfected neurons against oxidative insults, we co-transfected pSuper-Nogo-A or pSuper-panNogo with pEGFP-N1 vector in acutely isolated cortical neurons. ${ }^{16}$ Two shRNAs could effectively knockdown rat Nogo-A in PC12 cells (Figure $3 a$ ) and cortical neurons (Figure $3 b$ ). Silencing of neuronal Nogo-A spontaneously induced cell death and significantly increased susceptibility to $\mathrm{H}_{2} \mathrm{O}_{2}$ as revealed by $\mathrm{PI}$ staining in GFP-positive cells (Figure $3 \mathrm{c}$ ). Moreover, MTT assay showed a similar result for neurons transfected with an effective siRNA (Figure 3d). These facts suggest that neuronal amino-Nogo-A is essential for neuronal survival in oxidative stress.

Nogo-66-NgR/LINGO-1 and RhoA-ROCK signaling pathway are not involved in the neuroprotection. Previous studies have revealed that many known regulatory roles of Nogo-A rely on Nogo-66-NgR/p75/ LINGO-1-RhoA-ROCK pathway, ${ }^{2}$ which are reported to play important roles in several neuronal death models. ${ }^{17-20}$ We then assessed whether these components participated in the neuroprotection. Cell death assay showed no significant difference from that of control with several different signaling blockers, such as $1 \mathrm{E} 8$ and $2 \mathrm{~B} 3 \mathrm{mAb}$ against Nogo-A, ${ }^{15}$ TAT-NEP1-40 (Nogo extracellular peptide, residues 1-40), ${ }^{20}$ soluble LINGO-1-Fc ${ }^{18}$ and TAT-C3 protein (Figures $4 a-d$ ).

However, accumulating evidence reveals the close link between ROS generation and Rho GTPase cascade in some non-neuronal cells. ${ }^{21}$ Our in situ GST pull-down analysis ${ }^{15}$ showed that the activity of RhoA and Rac1/Cdc42 at different indicated time points did not differ from that of control with treatment of either $\mathrm{H}_{2} \mathrm{O}_{2}$ or TAT-AM (Figure $4 \mathrm{e}$ ). Taken together, these data implicate that Nogo-66-NgR/LINGO-1 and RhoA-ROCK signaling pathway do not link to aminoNogo-A-mediated pro-survival role.

The 290-562 residues are the pivotal domain of aminoNogo-A-mediating neuroprotection. According to the hot spot for proteases ${ }^{22}$ and the neurite outgrowth inhibitory domain, ${ }^{3}$ a series of deletions were used to map the regions responsible for the functional specificities of amino-Nogo-A (Figure 5a). Cell death assay indicated that M1 (aa 186-864), M2 (aa 186-562), M5 (aa 290-864) and M9 (aa 290-562) were important for the pro-survival effect (Figure 5b). Among them, the regions of $\mathrm{M} 2$ and $\mathrm{M} 9$ do not have an overlap with M6 (aa 564-749), which is a putative active domain. ${ }^{3,5}$ As shown in the graph, two pieces of M9 (M7, aa 290-400 and M8, aa 401-562) demonstrated only minor effects; thus, we narrowed down the shortest functional domain to residues 290-562, which is different from NiG- $\Delta 20$ (Figure 5b).

We noticed that some smaller fragments were detected in our western blot data of cerebral cortex tissues and subcellular fractions from primary cortical neurons (Supplementary Figures S5a and b). Especially, a $48 \mathrm{kDa}$ band could be recognized by the A201 antibody, not A563 (epitope mapping at aa 563-627) (Supplementary Figure S5a). It seems that the $48 \mathrm{kDa}$ fragment may contain residues 290-562.

Western blot with A201 antibody showed that $48 \mathrm{kDa}$ and some other degraded bands existed in normal neurons, and these bands disappeared after $\mathrm{H}_{2} \mathrm{O}_{2}$ treatment (Figure $5 \mathrm{c}$, 

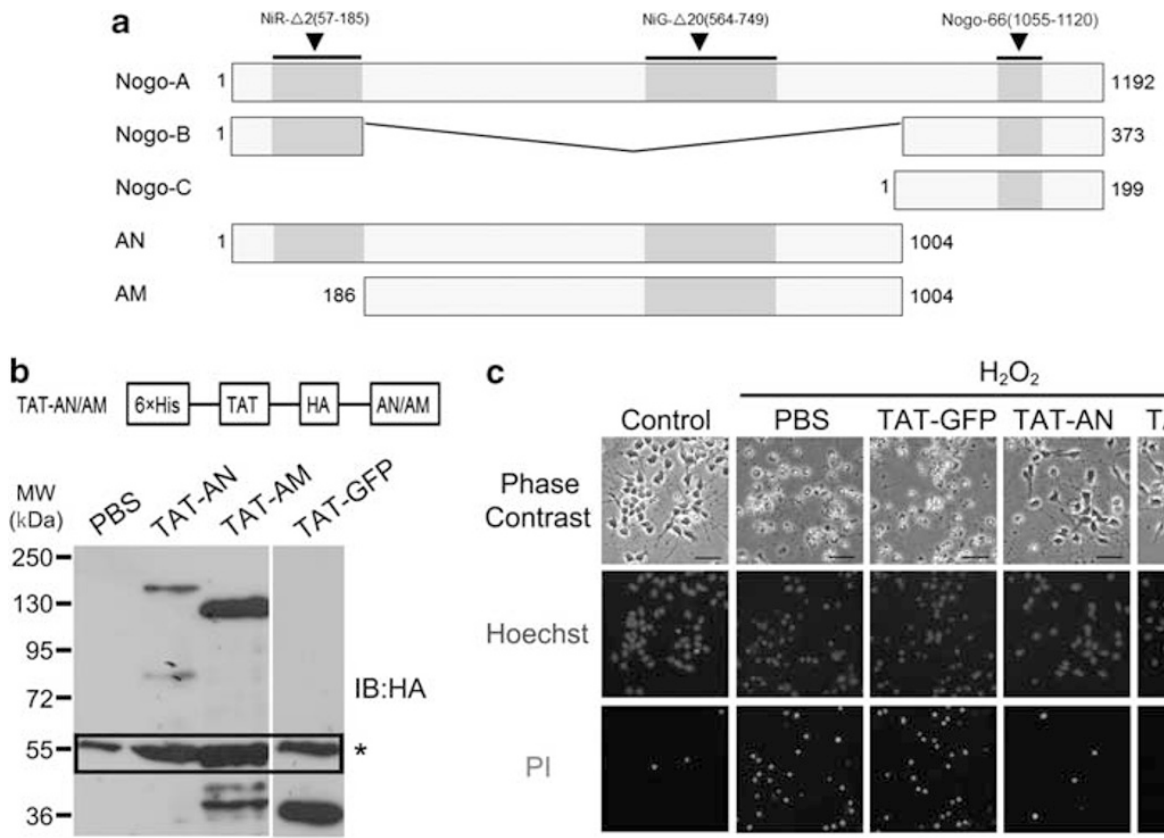

C

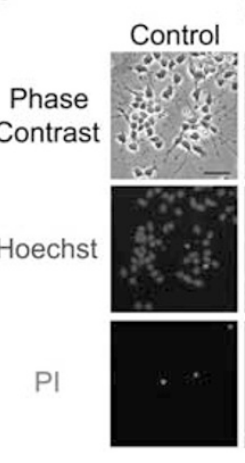

$\mathrm{H}_{2} \mathrm{O}_{2}$
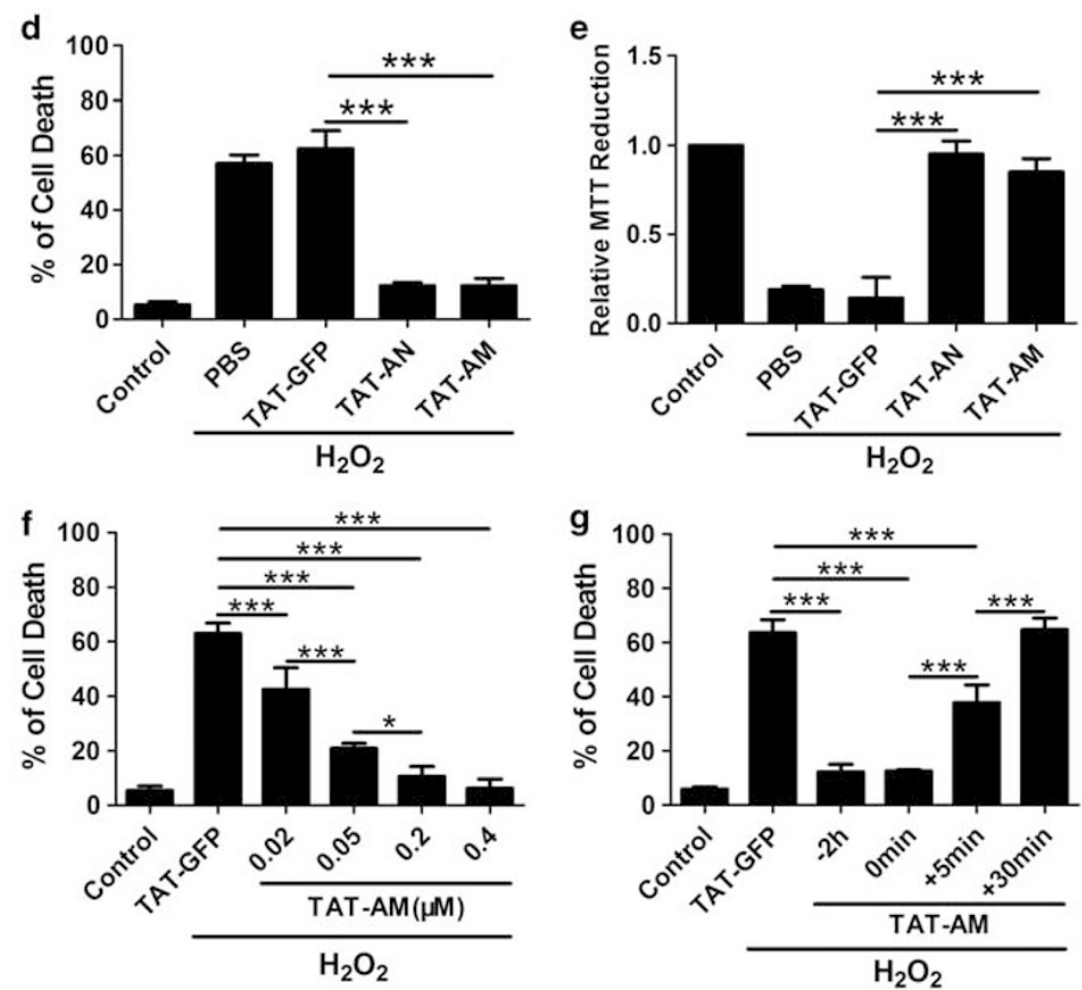

Figure 2 Pretreatment of HIV-1 trans-activating (TAT)-amino-Nogo-A protects cortical neurons against hydrogen peroxide $\left(\mathrm{H}_{2} \mathrm{O}_{2}\right)$-induced cell death. $($ a) $\mathrm{Schematic}$ presentation of the Nogo proteins. Human Nogo-A, amino acids (aa) 1-1192; Nogo-B, aa 1-373; and Nogo-C, aa 1-199. N terminus aa 1-185 is shared by Nogo-A and Nogo-B; $\mathrm{C}$ terminus aa 188 is the reticulon homology domain within Nogo-A/B/C and other reticulon family members. AN, the full-length amino-Nogo containing 1-1004 residues; AM, the 186-1004 residues unique to Nogo-A. (b) Top: pTAT-HA-AN/AM expression vector. $6 \times$ His, 6 His domain mediates protein binding to Ni ${ }^{2+}$ column; TAT, HIV-1-trans-activating short peptide helps protein enter cells; HA, a tag inserted for subsequent protein detection. AN/AM, insertion of desired cDNA using the restriction enzymes. Lower: neuron lysates treated with PBS, TAT-GFP, TAT-AN and TAT-AM for $2 \mathrm{~h}$ were blotted using anti-HA antibody. Corresponding bands at 150, 130 and $36 \mathrm{kDa}$ represented TAT-AN, TAT-AM and TAT-GFP, respectively, and the black rectangle represented the nonspecific bands of anti-HA antibody. (c) Under phase-contrast microscopy, numerous neurons exposed to $50 \mu \mathrm{M}$ $\mathrm{H}_{2} \mathrm{O}_{2}$ for $12 \mathrm{~h}$ exhibited damaged signs, disappeared cell body with brightening and protruding nuclei and discontinuous neurites. However, neurons with TAT-AN or TAT-AM pretreatment remained as normal. (d) The percentage of cell death rate was calculated by propidium iodide $(\mathrm{PI})(+) /$ Hoechst $(+)$. (e) Cell death rate was also examined by 3-(4,5dimethyldiazol-2-yl)-2,5-diphenyltetrazolium bromide (MTT) assay. (f) The cultured neurons were pre-incubated with TAT-AM at 0, 0.02, 0.05, 0.2 and $0.4 \mu \mathrm{M}$ for $2 \mathrm{~h}$, followed with $\mathrm{H}_{2} \mathrm{O}_{2}$ treatment. Cell death rate was calculated through $\mathrm{PI}(+) /$ Hoechst $(+)$. (g) TAT-AM $(0.2 \mu \mathrm{M})$ was added to the neuron cultures before $2 \mathrm{~h}$, simultaneously or post 5 or 30 min of $\mathrm{H}_{2} \mathrm{O}_{2}$ treatment. Cell death rate was calculated through $\mathrm{PI}(+) / \mathrm{Hoechst}(+)$. Bar $=50 \mu \mathrm{m} . n=4$, mean \pm S.D., one-way analysis of variance $\left(\right.$ ANOVA), ${ }^{\star} P<0.05 ;{ }^{* * \star} P<0.001$ 

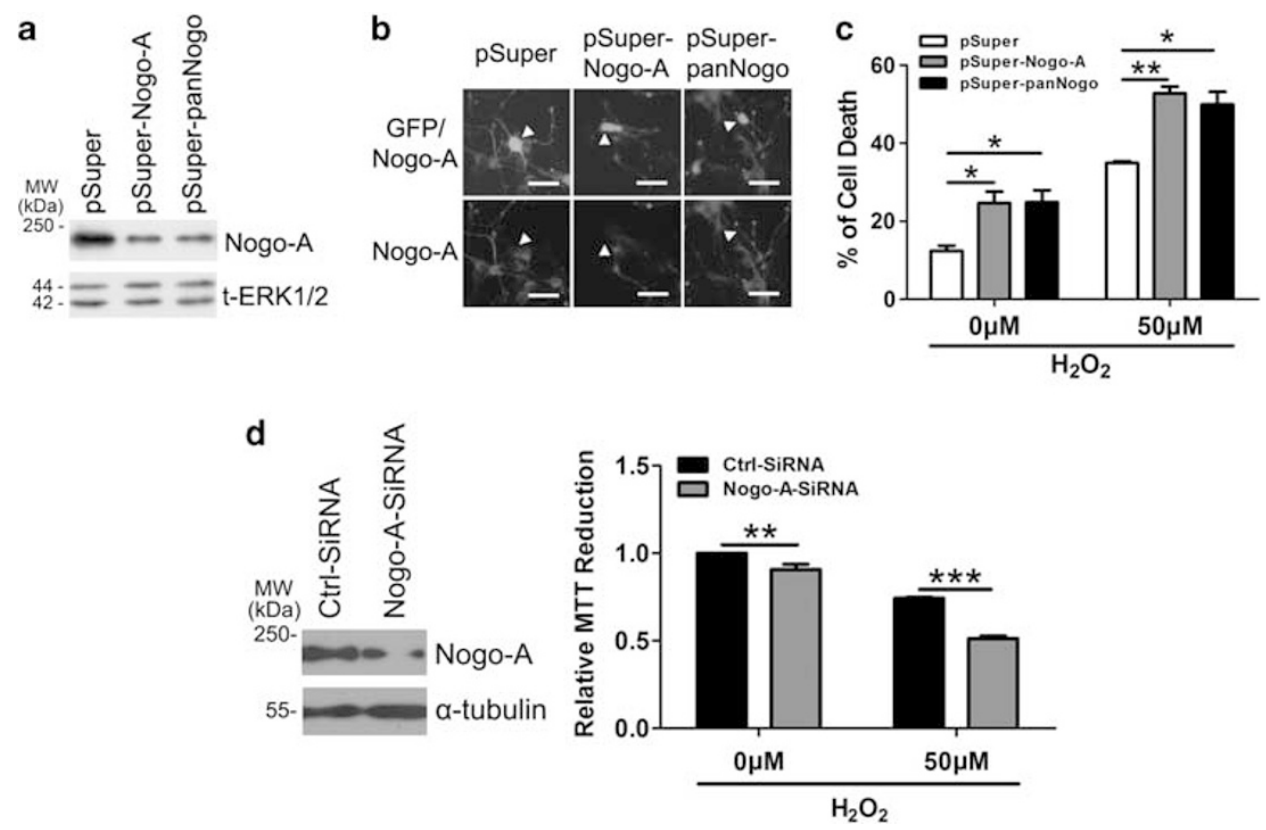

Figure 3 Downregulation of Nogo-A increases the neuronal susceptibility to oxidative stress. (a) Rat-derived PC12 cells transfected with pSuper, pSuper-Nogo-A and pSuper-panNogo for $48 \mathrm{~h}$ were lysed and immunoblotted with polyclonal antibody (pAb) A620. Total extracellular signal-regulated kinase 1/2 (t-ERK1/2) was selected as a loading control. (b) Cortical neurons co-transfected (arrow head) with pEGFP-N1 and the small hairpin RNA (shRNAs) above for $48 \mathrm{~h}$ were immunostained with pAb A620. (c) After transfection for $48 \mathrm{~h}$ as described in (b), neurons were treated with 0 or $50 \mu \mathrm{M}$ hydrogen peroxide $\left(\mathrm{H}_{2} \mathrm{O}_{2}\right)$ for $12 \mathrm{~h}$, cell death rate was determined by propidium iodide (PI) $(+) / E G F P(+)$. (d) Neurons were transfected with ctrl-small interfering RNA (siRNA) and Nogo-A-siRNA for $48 \mathrm{~h}$, and cell lysates were blotted with pAb A620 (left). After transfection for $48 \mathrm{~h}$ as described in (d), 0 or $50 \mu \mathrm{M} \mathrm{H}_{2} \mathrm{O}_{2}$ was added into cell culture for another $12 \mathrm{~h}$, cell death rate was determined by 3-(4,5-dimethyldiazol-2-yl)-2,5diphenyltetrazolium bromide (MTT) assay. Bar $=50 \mu \mathrm{m} . n=3$, mean \pm S.D., one-way analysis of variance (ANOVA), ${ }^{*} P<0.05 ;{ }^{* *} P<0.01 ;{ }^{* \star \star} P<0.001$

right panel, lanes 1 and 3). In the lysate from TAT-AM-treated neurons, the full-length $(130 \mathrm{kDa})$ and some proteolytic fragments, including $48 \mathrm{kDa}$, could be detected (Figure $5 \mathrm{c}$, right panel, lanes 2 and 4 ). The 130 and $48 \mathrm{kDa}$ fragments were also recognized by anti-HA antibody (Figure $5 \mathrm{c}$, left panel). Furthermore, the $48 \mathrm{kDa}$ band was also detected in HEK293FT-overexpressing Nogo-A, and it decreased gradually with increased $\mathrm{H}_{2} \mathrm{O}_{2}$ concentrations (Figure $5 \mathrm{~d}$ ).

Amino-Nogo-A inhibits intracellular ROS generation induced by $\mathrm{H}_{2} \mathrm{O}_{2}$. As known, once $\mathrm{H}_{2} \mathrm{O}_{2}$ enters the cell, it will lead to abundant ROS generation and then initiate a series of signaling pathways. ${ }^{23}$ In this part, we determined whether amino-Nogo-A could reduce cellular ROS to exert its protection against oxidative death. Cellular ROS levels were detected with dihydroethidium (DHE). Fluorescence image displayed that pretreatment and co-treatment of TAT-AM could quickly reduce $\mathrm{H}_{2} \mathrm{O}_{2}$-induced ROS (Figures $6 \mathrm{a}$ and b). The ROS pattern matched well with the previous timedependent neuroprotection of TAT-AM (Figure 2g). In addition, ROS detection for knockdown and deletion experiments also implicated the close relationship between the scavenging ability of ROS and neuroprotection (Figures 6c and d). Therefore, it strongly implicates that neuronal resistance to $\mathrm{H}_{2} \mathrm{O}_{2}$ is achieved through preventing or clearing the production of ROS by amino-Nogo-A.

ERK signaling pathway is partially involved in aminoNogo-A-mediated neuronal protection. ERK1/2 is a major mediator of oxidative stress. ${ }^{24}$ The western blot data showed that amino-Nogo-A could obviously suppress phosphorylation of ERK2 (p-ERK2) following 5-30 min of $\mathrm{H}_{2} \mathrm{O}_{2}$ stimuli (Figure 7a). However, unlike TAT-AM, a specific ERK1/2 inhibitor, U0126 only exhibited a weak neuroprotection (Figures $7 \mathrm{~b}$ and $\mathrm{c}$ ). Therefore, these data demonstrate that inhibition of $p$-ERK partially participates in the neuroprotection of amino-Nogo-A against $\mathrm{H}_{2} \mathrm{O}_{2}$-induced cell death.

AKT pathway has been shown to promote cell survival. ${ }^{25}$ Our western blot data show that AKT phosphorylation slightly increased in the early stage of $\mathrm{H}_{2} \mathrm{O}_{2}$ treatment (30 min), and it was not influenced by TAT-AM (Supplementary Figure S6), indicating that the protective effect of amino-Nogo-A was unlikely to be mediated by the AKT pathway.

$\mathrm{Bcl}-2$ is a pro-survival protein and some studies implicate the relation between $\mathrm{Bcl}-2$ and $\mathrm{ROS}^{26}$ As expected, western blot showed that TAT-AM could prevent the decrease of Bcl-2 expression induced by $\mathrm{H}_{2} \mathrm{O}_{2}$ (Figure 7d). These findings strongly support that neuronal amino-Nogo-A antagonizes oxidative damage through regulating ROS and its downstream.

Amino-Nogo-A resists to $\mathrm{H}_{2} \mathrm{O}_{2}$ via interacting with Prdx2. After observing that Nogo-A reduced ROS intensively, we further examined whether pretreatment of amino-Nogo-A influenced the expression of antioxidant genes. RT-PCR for 16 oxidoreductases showed that there was no obvious difference between TAT-AM and PBS group (Supplementary Figure S7). As pretreatment or co-treatment of amino-Nogo-A exerted the equivalent 

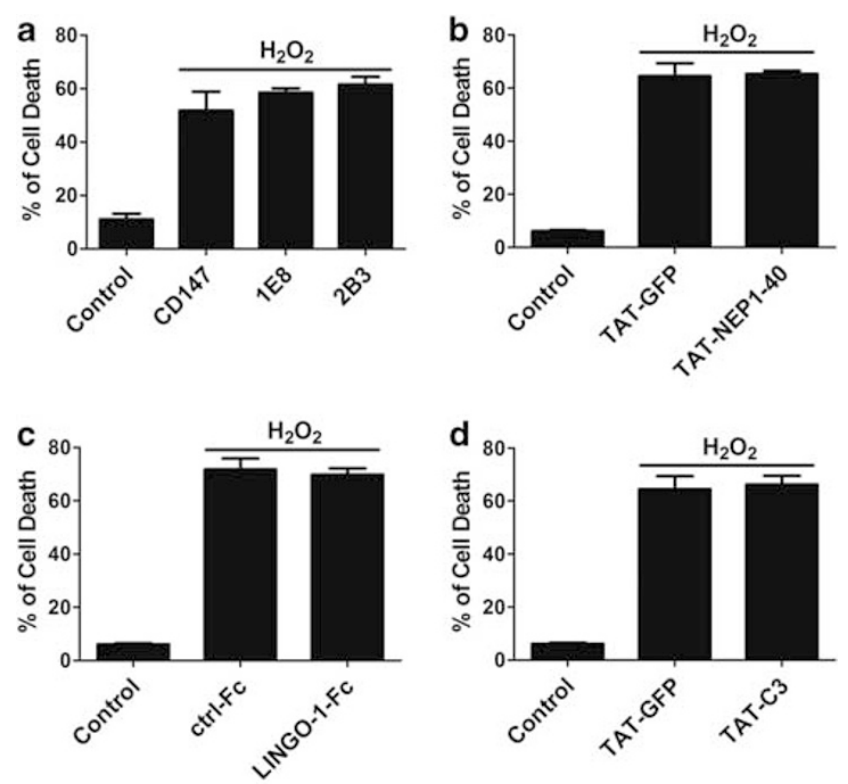

e

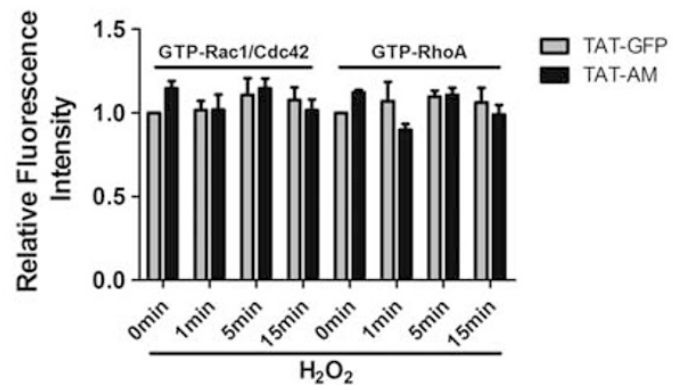

Figure 4 Nogo-66-NgR/LINGO-1 and RhoA-ROCK signaling pathways are not involved in the neuroprotection. 1E8 and 2B3 (a), HIV-1 trans-activating (TAT)NEP1-40, Nogo extracellular peptide, residues 1-40 (b), LINGO-1-Fc (c) and RhoA inhibitor TAT-C3 transferase (TAT-C3) (d) were added to cell culture, followed by $50 \mu \mathrm{M}$ hydrogen peroxide $\left(\mathrm{H}_{2} \mathrm{O}_{2}\right)$ incubation for $12 \mathrm{~h}$ in the presence of these proteins, cell death assay was performed by propidium iodide $(\mathrm{PI})(+) /$ Hoechst $(+)$. CD147 antibody, TAT-GFP and ctrl-Fc protein were selected as controls, respectively. (e) Active Rac1/Cdc42 and RhoA were detected by glutathione $S$-transferase (GST)-PBD and GST-RBD using in situ GST pull-down assay for neurons incubated in $50 \mu \mathrm{M} \mathrm{H}_{2} \mathrm{O}_{2}$ for indicated time with TAT-AM or not and then quantified. $n=4$, mean \pm S.D.

protective effects on neurons exposed to $\mathrm{H}_{2} \mathrm{O}_{2}$, we supposed that amino-Nogo-A might be a direct regulator of some oxidoreductases.

Prdxs are a family of ubiquitous peroxidase in which redoxactive cysteine (Cys) residues participate in the reduction of $\mathrm{H}_{2} \mathrm{O}_{2}$, and one subtype Prdx2 is primarily expressed in neurons. ${ }^{27}$ Western blot data demonstrated that neurons incubated with TAT-amino-Nogo-A reduced $\mathrm{Prdx} 2-\mathrm{SO}_{3}$ level in the presence of $\mathrm{H}_{2} \mathrm{O}_{2}$ or not (Figures $8 \mathrm{a}$ and $b$ ). Our results did not demonstrate a marked change of Prdx2 mRNA (Supplementary Figure S7) and protein (Figures 8a and b) from cortical neurons pre-incubated with TAT-AM, and thus we tried to seek some evidence for interaction between amino-Nogo-A and Prdx2. In cultured cortical neurons, the $\mathrm{Ni}^{2+}$ pull-down assay revealed that TAT-AM, but not TAT-GFP could pull down Prdx2-SO $\mathrm{S}_{3}$ (Figure $8 \mathrm{c}$ ). With an in vitro reciprocal GST pull-down assay, GST-AM could bind to Prdx2 (Figure 8d) and GST-Prdx2 could precipitate GFP-M1-WT (Figure 8e).

Cell death analysis showed that TAT-Prdx2 indeed played a protective role on oxidative damage (Figure 8f) and this action was also dependent on scavenging of ROS (Figure 8g). Then, amino-Nogo-A lost its resistance to oxidative stress in Prdx2 knockdown neurons (Figure 8h).

Furthermore, pretreatment of TAT-AM failed to protect low $\mathrm{KCl}$-induced cerebellar granule neurons (CGN) death (Supplementary Figure S8a) and tunicamycin-induced cortical neurons damage (Supplementary Figure S8b). Taken together, amino-Nogo-A specially prevents neurons from oxidative stress though interaction with Prdx2.

Cys residues at 424,464 and 559 of amino-Nogo-A mediate the interaction with Prdx2. Bioinformatics analyses do not provide clues for possible functional domains and motifs in the M9 active region. Three conserved Cys residues 424, 464 and 559 (Supplementary Figure S9) are just located in the pivotal neuroprotective domain of 290-562 residues. We constructed two Cys-Ala mutations, TAT-M1-3CA $\left(\mathrm{C}^{424} \mathrm{~A}, \mathrm{C}^{464} \mathrm{~A}\right.$ and $\left.C^{559} A\right)$ and TAT-M1-2CA $\left(C^{424} A\right.$ and $\left.C^{464} A\right)$. Cell death assay showed that, even though equivalent amount of TAT-M1-WT, TAT-M1-3CA and TAT-M1-2CA were added into neurons cultures (Figure 8i, top panel), pro-survival effect of the two mutations markedly lost compared with TAT-M1-WT (Figure 8i, lower panel). ROS detection implicated that the two mutations also failed to eliminate ROS production induced by $\mathrm{H}_{2} \mathrm{O}_{2}$ (Figure 8j). In Neuro2a cell model, cell death assay showed that overexpression of GFP-M1-WT, not GFP-M1$3 \mathrm{CA}$, exerted the protection against oxidative stress (Supplementary Figures S10a and b).

Biotin-conjugated iodoacetamide (BIAM), which could selectively alkylate $C y s$, was used to label proteins containing active Cys. ${ }^{28}$ M9-3CA, owing to the lack of Cys, did not bind to BIAM (data not shown). The BIAM-bound M9-WT decrease after $\mathrm{H}_{2} \mathrm{O}_{2}$ treatment (Figure 8k) suggested that Cys residues in $\mathrm{M} 9$ were sensitive to $\mathrm{H}_{2} \mathrm{O}_{2}$.

These data strongly support that $\mathrm{H}_{2} \mathrm{O}_{2}$-sensitive Cys residues of amino-Nogo-A may mediate the cross-talk between Nogo-A and Prdx2, and this biological behavior can accelerate the oxidation-reduction cycle of Prdx2.

\section{Discussion}

Nogo-A exhibits high expression levels in the developing CNS neurons. ${ }^{6-8}$ However, its pathophysiological role has remained unclear. Here, we showed for the first time evidence establishing a novel cell-autonomous neuroprotective role of amino-Nogo-A against oxidative stress (e.g., $\mathrm{H}_{2} \mathrm{O}_{2}$ ) and identifying a mechanism of amino-Nogo-A-mediated signaltransduction pathway of scavenging ROS (Figure 8I). $\mathrm{H}_{2} \mathrm{O}_{2}$ treatment induces ROS generation and oxidizes Prdx2. Amino-Nogo-A interacts with and reduces oxidized Prdx2 in a Cys-dependent manner. The cellular ROS production and ERK activation are inhibited, and thus amino-Nogo-A exerts resistance to oxidative insults. Our results support the notion that potential function of intraneuronal Nogo protein may be related to basic biological process such as cell survival. ${ }^{2}$ 

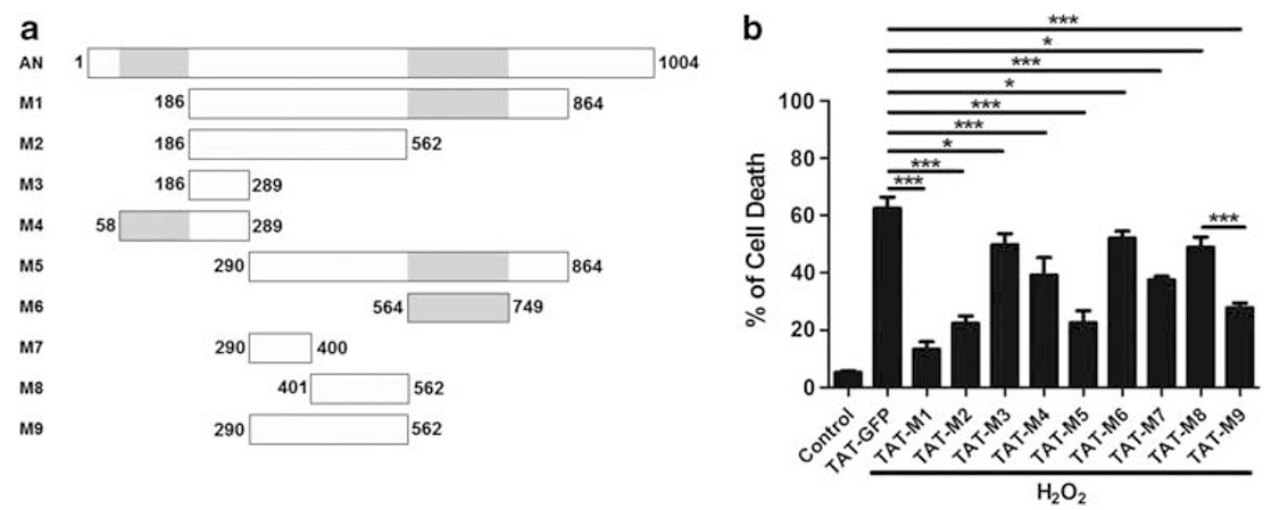

C
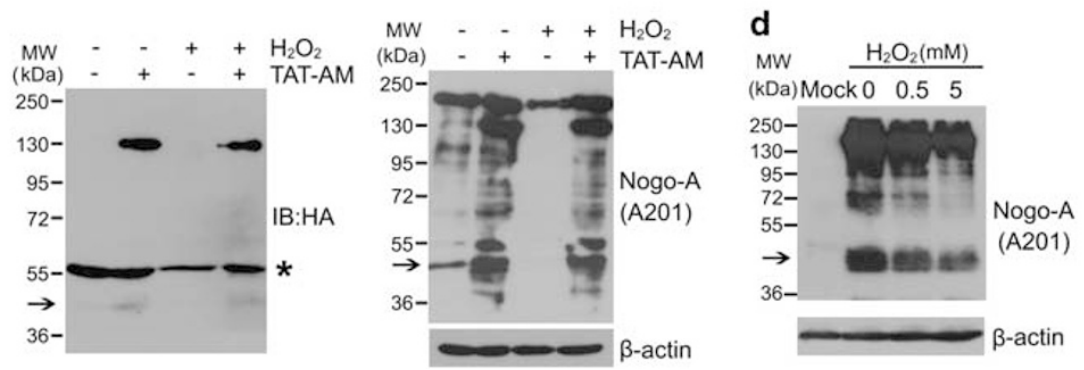

Figure 5 In all, 290-562 residues are the pivotal domain of amino-Nogo-A for resisting to oxidative damage. (a) Schematic diagram of different deletions (M1-M9) of amino-Nogo. (b) Neurons were pretreated with $0.2 \mu \mathrm{M} \mathrm{HIV}-1$ trans-activating (TAT)-M1-M9 for $2 \mathrm{~h}$, followed by exposure to $50 \mu \mathrm{M}$ hydrogen peroxide $\left(\mathrm{H}_{2} \mathrm{O}_{2}\right)$ for another $12 \mathrm{~h}$ in the presence of TAT-M1-M9. Cell death rate was calculated by propidium iodide $(\mathrm{PI})(+) / \mathrm{Hoechst}(+)$. (c) Lysates from neurons treated by $\mathrm{H}_{2} \mathrm{O}_{2}$ with or without TAT-AM was performed to western blot with anti-HA and A201 antibodies. $\beta$-Actin was selected as a loading control. *Presented the nonspecific bands of anti-HA antibody. (d) HEK293FT transfected with mock or full-length human Nogo-A were treated with indicated concentrations of $\mathrm{H}_{2} \mathrm{O}_{2}$ for $1 \mathrm{~h}$, and cell lysates were subjected to western blot probed with A201 antibody. $\beta$-Actin was selected as a loading control. The $48 \mathrm{kDa}$ bands were pointed with arrow; $n=4$, mean \pm S.D., one-way analysis of variance (ANOVA), ${ }^{*} P<0.05 ;{ }^{* * *} P<0.001$

a

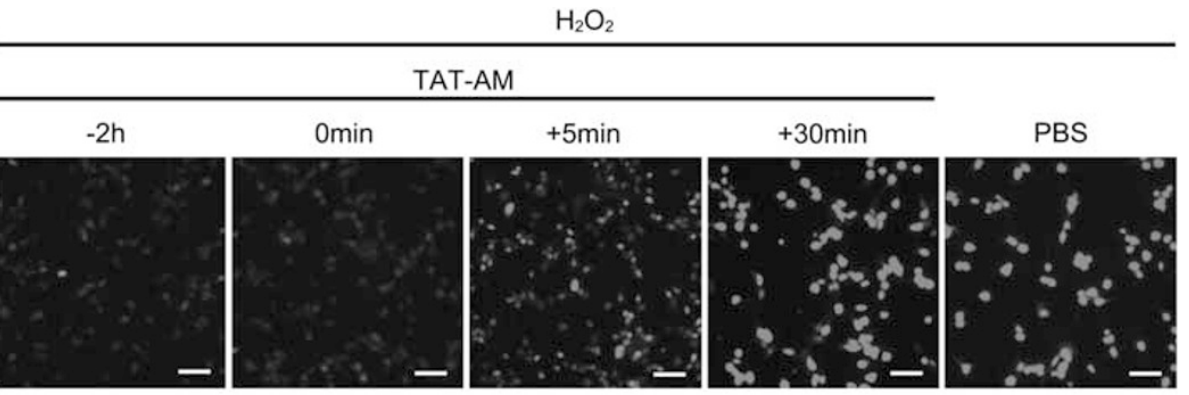

b

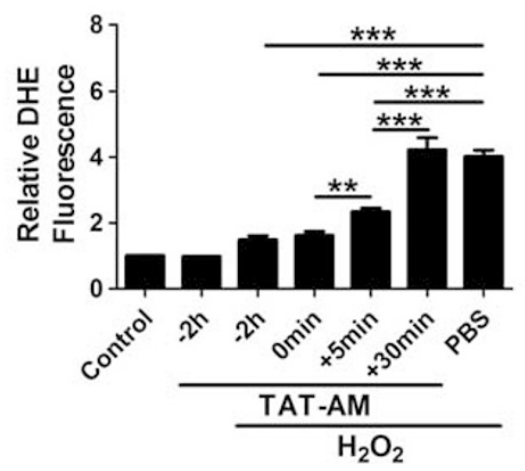

c

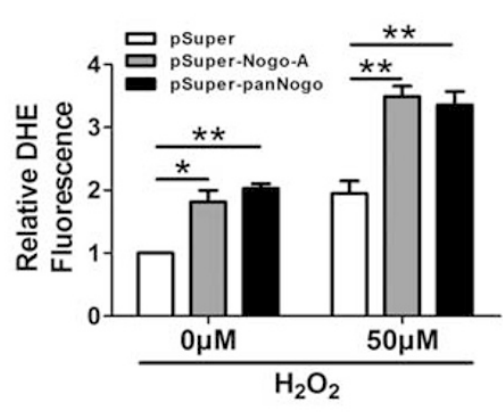

d

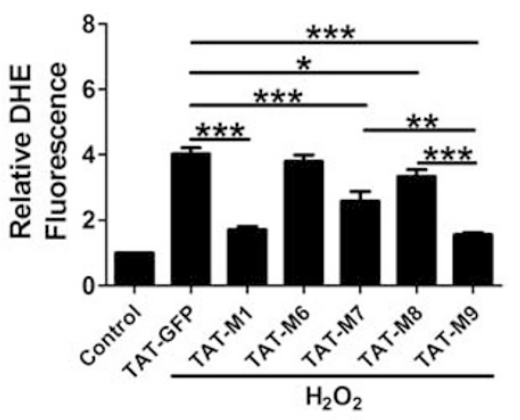

Figure 6 HIV-1 trans-activating (TAT)-amino-Nogo-A reduces intracellular reactive oxygen species (ROS) induced by hydrogen peroxide $\left(\mathrm{H}_{2} \mathrm{O}_{2}\right)$. A measure of $0.2 \mu \mathrm{M}$ TAT-AM was added to the neuron cultures before $2 \mathrm{~h}$, simultaneously or post 5 or 30 min of $50 \mu \mathrm{M} \mathrm{H}_{2} \mathrm{O}_{2}$ treatment for $2 \mathrm{~h}$, and ROS level was examined by dihydroethidium (DHE) under fluorescence microscope (a) and statistically analyzed (b). ROS examination was also performed in transfected neurons with small hairpin RNAs (shRNAs) against Nogo-A (c) and amino-Nogo deletions (d). Bar $=50 \mu \mathrm{m}, n=3$, mean \pm S.D., one-way analysis of variance (ANOVA), ${ }^{\star} P<0.05 ;{ }^{* \star} P<0.01$. ${ }^{\star \star \star} P<0.001$ 

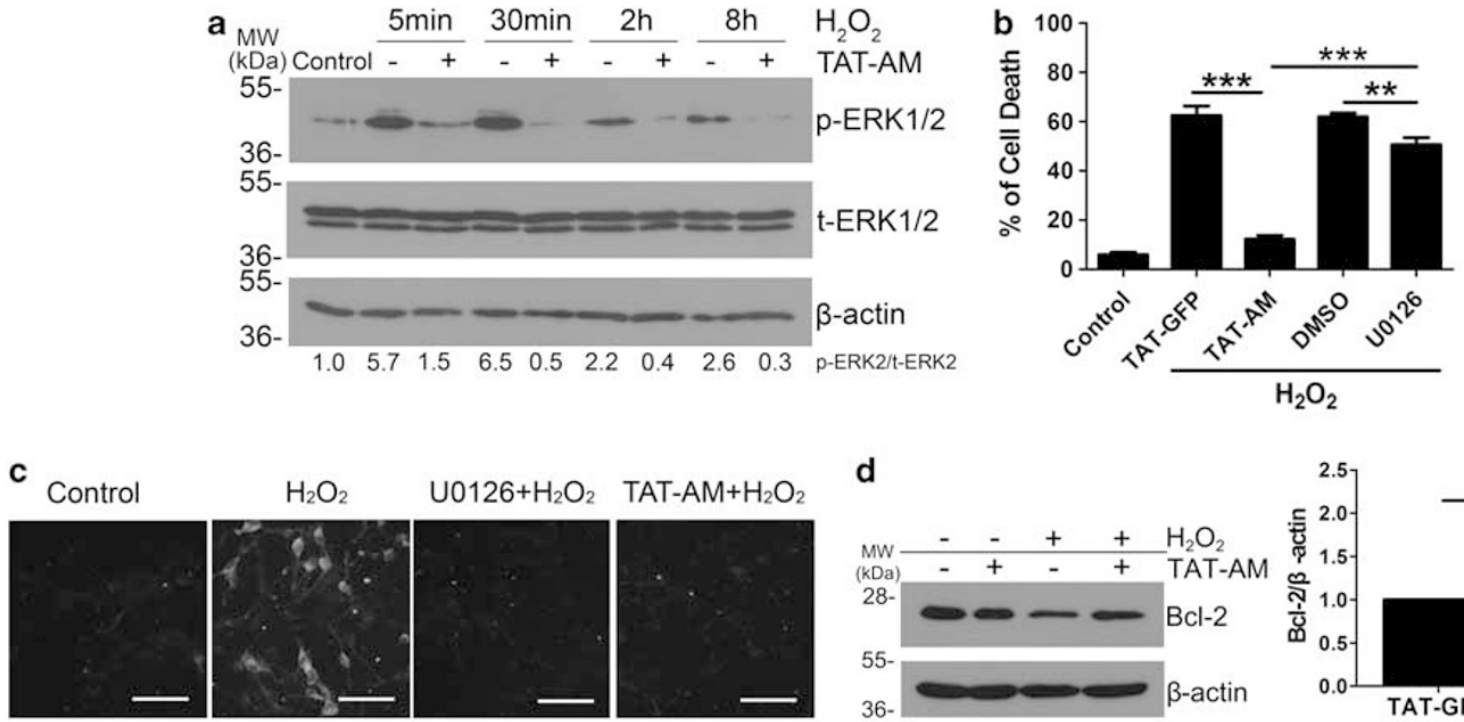

$\mathrm{U} 0126+\mathrm{H}_{2} \mathrm{O}_{2}$
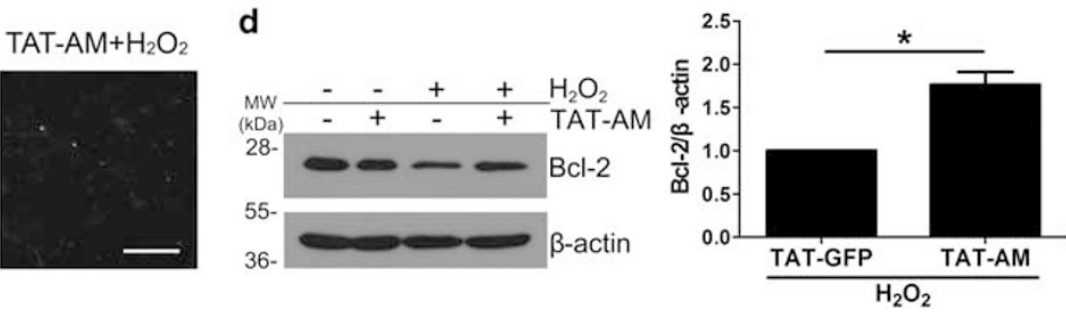

Figure 7 Amino-Nogo-A suppresses extracellular signal-regulated kinase 2 (ERK2) activation and $\mathrm{Bcl}-2$ reduction induced by hydrogen peroxide $\left(\mathrm{H}_{2} \mathrm{O}_{2}\right)$. (a) $\mathrm{Cell}$ lysates collected from neuron cultures treated with $50 \mu \mathrm{M} \mathrm{H}_{2} \mathrm{O}_{2}$ for $5,30 \mathrm{~min}, 2$ and $8 \mathrm{~h}$ with or without pre-incubation of $0.2 \mu \mathrm{M} \mathrm{HIV-1}$ trans-activating (TAT)-AM were subjected to western blot using antibody against phosphorylated ERK1/2 (p-ERK1/2) or total ERK1/2 (t-ERK1/2). $\beta$-Actin was selected as an inner standard. Quantification by densitometric scans was presented by p-ERK/t-ERK. (b) Cortical neurons were pretreated with $0.2 \mu \mathrm{M} \mathrm{TAT}$-AM or $10 \mu \mathrm{M} U 0126$ for $2 \mathrm{~h}$, followed by exposure of $50 \mu \mathrm{M} \mathrm{H} \mathrm{H}_{2}$ for $12 \mathrm{~h}$, cell death rate was calculated as before. U0126, a specific inhibitor for MEK, was used to suppress ERK phosphorylation. TAT-GFP and dimethylsulfoxide (DMSO) were chose as the controls for TAT-AM and U0126, respectively. (c) In all, $10 \mu \mathrm{M}$ U0126 or $0.2 \mu \mathrm{M}$ TAT-AM were added to neuron cultures before exposure to $\mathrm{H}_{2} \mathrm{O}_{2}$ for 15 min, and then cells were performed by immunofluorescence staining with anti-p-ERK antibody. (d) Lysates from neurons treated by $\mathrm{H}_{2} \mathrm{O}_{2}$ for $8 \mathrm{~h}$ with or without TAT-AM pretreatment were performed to western blot with anti-Bcl-2 antibody. $\beta$-Actin was selected as a loading control. Quantification by densitometric scans was presented by $\mathrm{Bcl}-2 / \beta$-actin. Bar $=50 \mu \mathrm{m}, n=4$, mean \pm S.D., paired $t$-test, ${ }^{\star} P<0.05 ;{ }^{* \star} P<0.05 ;{ }^{* * \star} P<0.001$

In this study, several lines of evidence demonstrated that neuronal amino-Nogo-A prevented cortical neurons from oxidative damage. In cultured cortical neurons, endogenous Nogo-A mRNA and protein were significantly downregulated upon $\mathrm{H}_{2} \mathrm{O}_{2}$ exposure for $8 \mathrm{~h}$, and knockdown of Nogo-A resulted in more susceptibility to acute oxidative insults and markedly increased neuronal death. However, both transducible TAT-amino-Nogo-A and overexpressed amino-Nogo-A led to a strong neuroprotection. TAT protein transduction technology was used to identify the function of 'intra-neuronal' amino-Nogo-A in the oxidative cell death model. It is very difficult to resolve the issue by some working strategies such as Nogo-A antibodies neutralization, traditional Nogo-A KO mice and Nogo-A knockdown due to its intracellular localization and compensatory upregulation of Nogo-B. ${ }^{29}$ AminoNogo-A is present intracellularly in the developing cortical neurons, and more importantly, amino-Nogo-A is unstable in vitro and in vivo. ${ }^{22}$ Thus, TAT fusion proteins will be an effective tool to mimic the intracellular amino-Nogo-A. TAT-amino-Nogo-A and its several deletions such as M1, M2, M5 and M9 proteins containing aa 290-562 were successfully transduced into cortical neurons and exerted a strong neuroprotection against oxidative damage. Although we also observed that excess $\mathrm{H}_{2} \mathrm{O}_{2}$ could react with $\mathrm{M} 9$ in vitro (Figure 8k), to date, we had no evidence to demonstrate that $\mathrm{H}_{2} \mathrm{O}_{2}$ was completely depleted by amino-Nogo-A outside of cells (Supplementary Figure S11). Thus, these findings strengthen the view that neuronal amino-Nogo-A may function as a neuroprotective agent, specific to oxidative stress beyond the well-known neurite outgrowth inhibitor.
Some other investigations with Nogo-A/B KO mice ${ }^{30}$ in ALS animal model and Nogo-A-deficient mice or antibodymediated Nogo-A blockade in the reperfused ischemic brain ${ }^{31}$ seem partially consistent with our in vitro result. Importantly, pathological mechanism of these two disease models is linked to oxidative stress. ${ }^{14}$ For instance, deletion of Nogo-A/B gene accelerates motor neuron degeneration, ALS disease onset and progression. ${ }^{30}$ In the Nogo-A/B mutants, Nogo-C and other reticulon members in motor neurons are not affected, ${ }^{32}$ indicating that amino-Nogo-A may be involved in motor neuron survival, at least in the $S^{\mathrm{G} O D^{\mathrm{G}} 3 \mathrm{~A}}$ transgenic ALS mouse model.

Another study uncovers that in ischemic brain tissue, NogoA deactivation by genetic deletion or neutralizing antibody, $11 C 7$ (epitope aa 623-640, which lies within the NiG- $\Delta 20$ domain of amino-Nogo-A), goes along with decreased neuronal survival and more protracted neurological recovery. ${ }^{31}$ The authors proposed that amino-Nogo-A on oligodendrocyte surface may act through unknown receptors, for example, integrin ${ }^{4}$ in controlling neuronal survival in the ischemic brain. Very interestingly, in our in vitro model, TATM6 protein containing the epitope of $11 \mathrm{C} 17$ antibody (also $\mathrm{NiG}-\Delta 20$ ) did not show any neuroprotective effect (Figure $5 \mathrm{~b}$ ), although our unpublished data and some studies suggested that it could induce growth cone collapse. ${ }^{3}$ The data indicate that the sole NiG- $\Delta 20$ domain do not exert neuroprotection. It is very possible that the presence of NiG- $\Delta 20$ can enhance the penetration of amino-Nogo-A into neurons through integrins or other unknown receptor(s). Through the mechanism of receptor-mediated endocytosis, ${ }^{5}$ noTAT-AM protein, 
a

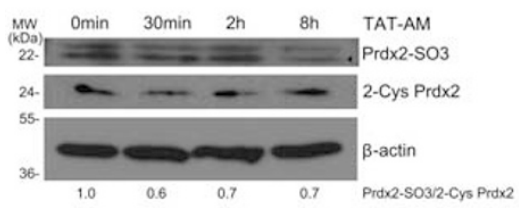

b

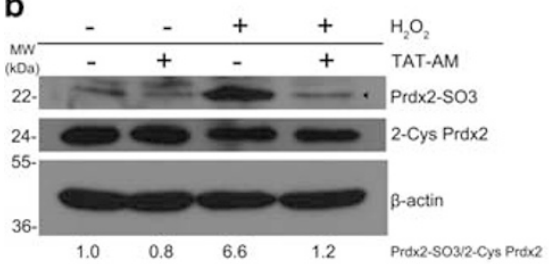

$\begin{array}{lllll}1.0 & 0.8 & 6.6 & 1.2 & \text { Prdx2-SO3/2-Cys Prox }\end{array}$
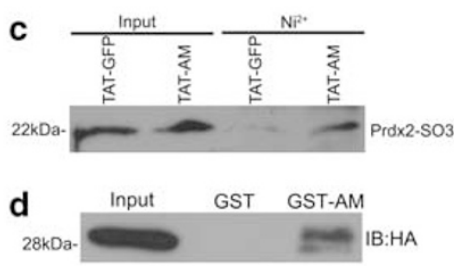

e

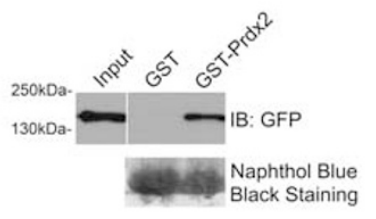

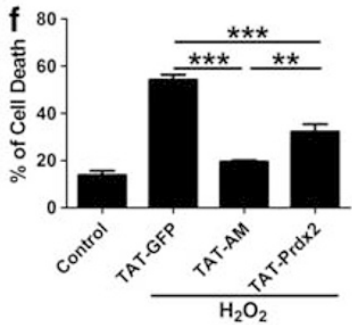

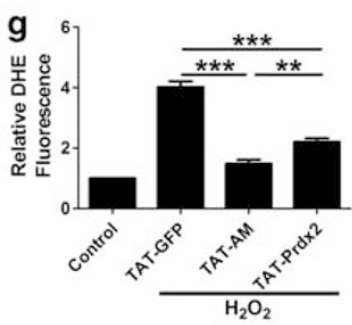

h
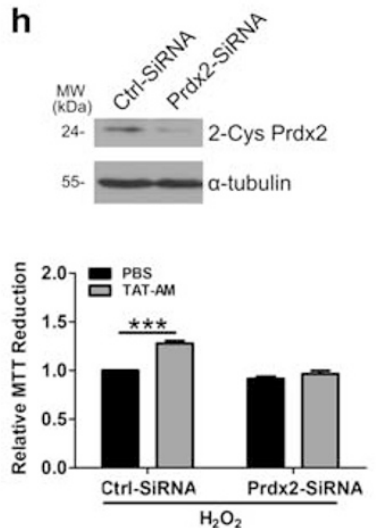

i
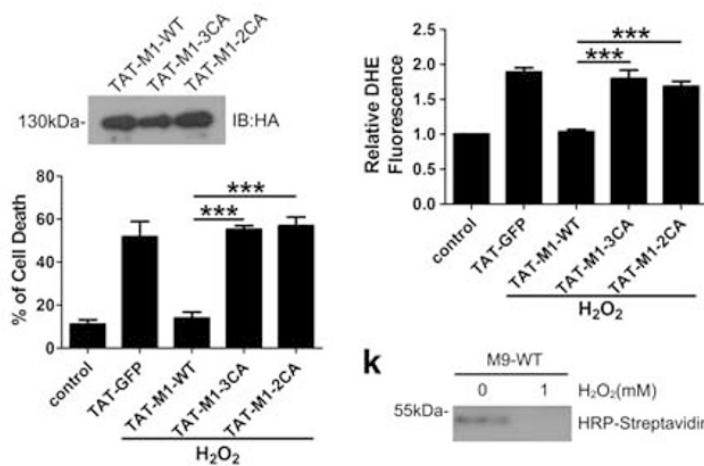

k

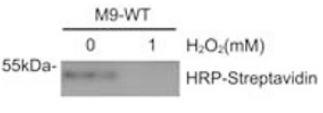

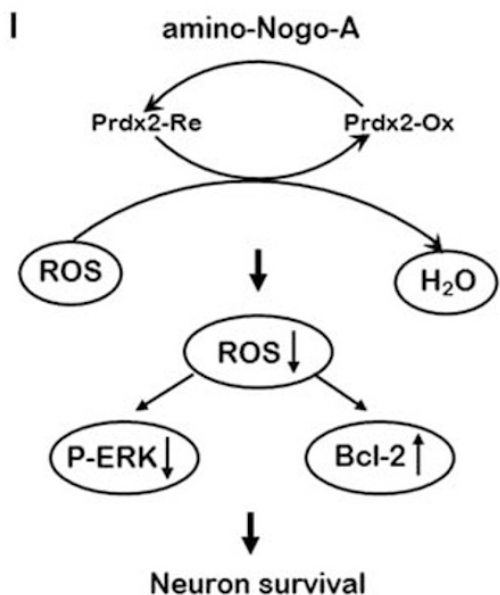

Figure 8 Amino-Nogo-A resists to hydrogen peroxide $\left(\mathrm{H}_{2} \mathrm{O}_{2}\right)$ via interacting with peroxiredoxin 2 (Prdx2). (a) Neurons were incubated with $0.2 \mu \mathrm{M} \mathrm{HIV-1}$ trans-activating (TAT)-AM for indicated time, and then cells lysates were performed to western blot with anti-Prdx2-SO3 and anti-2-cysteine (Cys) Prdx2 antibodies. $\beta$-Actin was selected as a loading control. (b) Lysates from neurons treated by $\mathrm{H}_{2} \mathrm{O}_{2}$ with or without TAT-AM were performed to western blot with anti-Prdx2-SO3 and anti-2-Cys Prdx2. $\beta$-Actin was selected as a loading control. (c) Cortical neurons were incubated with $0.2 \mu \mathrm{M}$ TAT-GFP or TAT-AM for $2 \mathrm{~h}$, and then were submitted to $\mathrm{Ni}^{2+}$ pull-down assay. Bound endogenous Prdx2-SO3 was analyzed by immunoblotting with anti-Prdx2-SO3 antibody. (d) Glutathione-Sepharose beads coupled with GST or GST-AM were incubated with TAT-HA-Prdx2. Bound Prdx2 was analyzed by immunoblotting with anti-HA antibody. (e) Glutathione-Sepharose beads coupled with GST or GST-Prdx2 were incubated with 293FT cell lysate overexpressed with GFP-M1-WT. Bound M1-WT was analyzed by immunoblotting with anti-GFP antibody. The amount of GST or GST-fusion Prdx2 was revealed by naphthol blue black staining. Neurons pretreated with TAT-Prdx2 or TAT-AM, followed by incubation in $\mathrm{H}_{2} \mathrm{O}_{2}$ was examined by cell death assay (f) and dihydroethidium (DHE) test $(\mathbf{g}$ ) as before. (h) Top: neurons transfected with ctrl-small interfering RNA (siRNA) and Prdx2-siRNA for $48 \mathrm{~h}$ were blotted with anti-2-Cys Prdx2 antibody. $\beta$-Actin was selected as a loading control. Lower: Neurons transfected with ctrl-siRNA and Prdx2-siRNA were pre-treated with TAT-AM followed by incubation in $\mathrm{H}_{2} \mathrm{O}_{2}$, and then cell death assay was calculated by 3-(4,5-dimethyldiazol-2-yl)-2,5-diphenyltetrazolium bromide (MTT) assay. (i) Top: neurons treated with $0.2 \mu \mathrm{M} \mathrm{TAT-M1-WT,}$ TAT-M1-3CA and TAT-M1-2CA for $2 \mathrm{~h}$ were lysed and immunoblotted with anti-HA antibody. The effect of the three proteins on oxidative damaged neurons was checked by cell death assay (lower in i) and DHE test (j). (k) In all, $100 \mathrm{ng}$ M9-WT pre-incubated with $1 \mathrm{mM} \mathrm{H}_{2} \mathrm{O}_{2}$ or not were labeled with biotin-conjugated iodoacetamide (BIAM) and then probed with horseradish peroxidase (HRP)-streptavidin. (I) Working model of amino-Nogo-A resisting to $\mathrm{H}_{2} \mathrm{O}_{2} \cdot n=4$, mean \pm S.D., one-way analysis of variance (ANOVA), ${ }^{* \star} P<0.01 ;{ }^{* \star \star} P<0.001$

removed of TAT protein transduction domain, retained relative neuroprotection (Supplementary Figures S3a and b). However, no experimental evidence demonstrates that aminoNogo-A can release from oligodendrocyte surface. As to the in vivo results, the facts that pretreatment of antibody $11 \mathrm{C} 7$ is internalized into intracellular vacuoles of neurons ${ }^{31,33}$ and neuronal Nogo-A knockout simultaneously occurs in Nogo-Adeficient mice ${ }^{31}$ support the concept that neuronal Nogo-A may participate in cell survival against oxidative stress in the ischemic model mice. In the future, construction of neuronalspecific knockout mice of Nogo-A or Nogo-A/B or transgenic mice of amino-Nogo-A, especially the domain of aa 290-562, will hopefully help to clarify these issues.
ROS accumulation may be a critical mediator of $\mathrm{H}_{2} \mathrm{O}_{2}$ neurotoxicity. Our study revealed novel molecular mechanisms of amino-Nogo-A scavenging ROS by interacting with oxidized Prdx2. Our in vitro cell death assay did not show a possibility of amino-Nogo-A acting as a peroxidase (data not shown). The oxidized form of Prdx2 is reverted back to the reduced form by thioredoxin (Trx), ${ }^{27}$ and thus if amino-Nogo-A scavenged ROS just like Trx? As expected, amino-Nogo-A could interact with Prdx2, and even precipitated Prdx2SO3. Pretreatment of amino-Nogo-A exactly reduced both endogenous and $\mathrm{H}_{2} \mathrm{O}_{2}$-induced $\mathrm{Prdx} 2-\mathrm{SO}_{3}$ level (Figures $8 \mathrm{a}-\mathrm{C}$ ). In addition, we also found that there was a conserved $\mathrm{CXXC}$ motif in amino-Nogo-A on the novel mapping functional region, 
290-562 residues (Supplementary Figure S9). All the deletions of amino-Nogo-A containing aa 290-562 were able to scavenge ROS in cellular level. Mutations for Cys of amino-Nogo-A failed to resist to $\mathrm{H}_{2} \mathrm{O}_{2}$ indicate that amino-Nogo-A was likely suspected as Trx to accelerate the regeneration of Prdx2. Although the exact mechanisms remain to be clarified, these findings offer new insights into possible mammalian-specific roles of amino-Nogo-A in oxidative neuronal death as a novel scavenger for ROS, through interacting with Prdx2 like Trx.

In summary, we discovered a critical role of amino-Nogo-A in the control of neuronal survival against oxidative insults in a cellautonomous manner. The mechanisms remain to be explored. Yet, these findings suggest a novel redox-related pathway of neuronal Nogo-A in regulating many important processes, that is, growth cone collapse, neural precursor migration, neural development, neuronal homeostasis and plasticity, and may also provide us new insights into the potential roles of aminoNogo-A in neurodegenerative diseases.

\section{Materials and Methods}

Animals. All animal procedures were approved by Animal Care Committee at Shanghai Jiao Tong University. Embryonic (E) 16-18 days, postnatally (P) 3, 7 and 15 days and adult Sprague-Dawley (SD) rats were obtained from Shanghai Slac Laboratory Animal Company (Shanghai, China).

Nogo-A antibodies. Several Nogo-A-specific antibodies were used in the study (Figure 1a). For immunofluorescence staining, a home-made polyclonal antibody A620 was used. ${ }^{7,15}$ For western blots, A620 and two commercial antibodies, A201 (Prosci, San Diego, CA, USA; no. 4089) and A563 (BD Biosciences PharMingen, San Diego, CA, USA; no. 612238) were used. For live cell surface staining, A620, A201 and 1E8 (ref. 15) were used. For cell death assay, 1E8 and 2B3 (ref. 15) were used.

DNA constructs. Several sets of oligonucleotides were designed for PCR amplification of full-length EGFP, Prdx2 and amino-Nogo-A deletions constructs, which were then inserted in vector PTAT-HA in fusion with the $6 \times$ His, TAT protein transduction domain and $\mathrm{HA}$ Tag (Figures $2 \mathrm{a}$ and $5 \mathrm{a}$ ). Briefly, the coding sequences of AN (aa 1-1004), AM (aa 186-1004), M1 (aa 186-864), M2 (aa 186-562), M3 (aa 186-289), M4 (aa 58-289), M5 (aa 290-864), M6 (aa 564-749), M7 (aa 290-400), M8 (aa 401-562) and M9 (aa 290-562) were amplified by LA-PCR from the KIAA0886 clone, the GFP was amplified from pEGFP-N1 parental vector (Clontech, Mountain View, CA, USA) and the Prdx2 was amplified from HA-Prdx2. All the PCR products were subcloned into PTAT-HA expression vector at $\mathrm{Ncol}$ and $X$ hol sites. The AM and Prdx2 fragments were also inserted to pGEX-KG vector to yield GST-AM and GST-Prdx2 expression constructs. NoTAT-AM was generated through TAT-AM digestion with BamHI and self-ligation. M1-WT or M1-3CA (see below) fragments were inserted to pEGFP-C3 vector (Clontech) to generate GFPM1-WT or GFP-M1-3CA. All constructs were confirmed by sequencing.

\section{Expression and purification of recombinant TAT and GST fusion proteins. Plasmids for TAT-HA or GST fusion proteins were transformed into the Escherichia coli strain BL21 (DE3). Protein production was induced with $100 \mu \mathrm{M}$ isopropyl $\beta$-D-1-thiogalactopyranoside (TaKaRa, Tokyo, Japan) at $16^{\circ} \mathrm{C}$ for $18 \mathrm{~h}$, and purified by Ni-NTA-agarose chromatography (Merck, Darmstadt, Germany) ${ }^{20}$ or glutathione-agarose chromatography (Sigma-Aldrich, St. Louis, MO, USA), respectively. ${ }^{7}$ The size and purity of all the proteins were confirmed by sodium dodecyl sulfate-polyacrylamide gel electrophoresis (SDS-PAGE), after dialysis and filtration, the proteins were subpackaged and stored at $-80^{\circ} \mathrm{C}$.}

Transduction of TAT fusion proteins in vitro. TAT fusion proteins have been previously shown to cross rapidly and efficiently into cultured cells and into tissues when injected into mice. Furthermore, proteins fused to TAT retain their biological activity. ${ }^{20}$ For the delivery of TAT fusion proteins into neurons, these fusion proteins, for example, $0.2 \mu \mathrm{M}$ TAT proteins, were added externally to the culture media for $2 \mathrm{~h}$ (other indicated concentrations and time courses were used in some experiments), and then followed by drug treatment in the presence of TAT fusion proteins. Transducible effect of TAT fusion proteins was analyzed by western blotting using anti-HA antibody.

Cell culture and transfection. Primary cortical neurons were prepared from brains of E16-18 days SD rats as described previously. ${ }^{34}$ Briefly, cerebral cortex was removed aseptically, and then digested and dispersed into single cells; after centrifugation, neurons were resuspended in Dulbecco's modified Eagle's medium (DMEM) with $10 \%$ fetal bovine serum (FBS) containing $2 \mathrm{mM}$ glutamine, and $1 \%$ penicillin and streptomycin (Invitrogen, Carlsbad, CA, USA) and then seeded at $1.25 \times 10^{5}$ cells per $\mathrm{cm}^{2}$ on 24- or 96-well plate or culture dishes (Corning Inc., Acton, MA, USA) coated with $100 \mu \mathrm{g} / \mathrm{ml}$ poly-L-lysine and incubated in humidified atmosphere with $5 \% \mathrm{CO}_{2}$ at $37^{\circ} \mathrm{C}$. After $2 \mathrm{~h}$, the whole medium was replaced with neurobasal medium (NB) containing $2 \%$ B27 supplement (Invitrogen), $2 \mathrm{mM}$ glutamine and $1 \%$ penicillin and streptomycin. For subcellular extraction and $\mathrm{Ni}^{2+}$ pull-down experiments, $1.5 \times 10^{7}$ cells per plate was seeded. All oxidative stress experiments were initiated $24-48 \mathrm{~h}$ after plating; among this time, ionotropic glutamate receptor-mediated neurotoxicity was not involved because of very low receptor expression. ${ }^{35}$ Transfection using Lipofectamine 2000 (Invitrogen) was carried out on acutely dissociated neurons before plating in DMEM, and $2 \mathrm{~h}$ later, the whole medium was replaced with NB/B27; oxidative stress-induced cell death experiment was performed after $48 \mathrm{~h}$ transfection. ${ }^{16}$

Three cell lines of HEK293FT (Invitrogen), PC12 (ATCC, no. CRL-1721) and Neuro2a (Institute of Biochemistry and Cell Biology, SIBS, CAS, Shanghai, China) were maintained in DMEM supplemented with $10 \% \mathrm{FBS}$, and $1 \%$ penicillin and streptomycin. HEK293FT and Neuro2a and PC12 cells transfection were performed with FuGENE HD reagent (Roche, Mannheim, Germany) and Lipofectamine 2000 (Invitrogen), respectively, according to the manufacturer's instructions.

Cell death assay. The cortical neurons were exposed to $\mathrm{H}_{2} \mathrm{O}_{2}$ or tunicamycin ${ }^{36}$ to induce cortical neuron death mediated by oxidative damage or ER stress, respectively. Different concentrations of $\mathrm{H}_{2} \mathrm{O}_{2}$ or tunicamycin were added to cell cultures for the indicated time, and then neurons were incubated in culture medium containing $5 \mu \mathrm{g} / \mathrm{ml} \mathrm{PI}$ and $5 \mu \mathrm{g} / \mathrm{ml}$ Hoechst at $37^{\circ} \mathrm{C}$ for $5 \mathrm{~min}$. Percentage of cell death was calculated by PI $(+) /$ Hoechst $(+)$. Low KCl-induced CGN cell death model was also used as described previously. ${ }^{37}$

MTT assay. Cell viability was assessed by measuring their ability to metabolize MTT, as described previously. ${ }^{38}$ Following the indicated treatments, cells were maintained in growth medium containing $0.5 \mathrm{mg} / \mathrm{ml} \mathrm{MTT}$ for $4 \mathrm{~h}$ at $37^{\circ} \mathrm{C}$. After removing the medium, DMSO was then added to each individual well. Following complete dissolution for $10 \mathrm{~min}$ at room temperature, absorbance at $490 \mathrm{~nm}$ was measured.

Measurement of ROS using DHE. As described previously, ${ }^{39}$ the cell penetrative DHE was used to assess real-time formation of superoxide in cortical neurons. DHE stocked in DMSO was added directly to the culture media at final concentration of $10 \mu \mathrm{M}$ at $37^{\circ} \mathrm{C}$ for $30 \mathrm{~min}$, and then neurons were rinsed once rapidly in PBS and immediately observed in fluorescence microscope (Leica DMI6000B, Leica Microsystems GmbH, Wetzlar, Germany) and analyzed by Image Pro-Plus software (IPP 6.0, MediaCybernetics, Silver Spring, MD, USA).

Immunocytochemistry. Cells on poly-L-lysine-coated glass coverslips were fixed with $4 \%$ paraformaldehyde for $15 \mathrm{~min}$ at room temperature and then permeabilized by treatment with ice-cold methanol for $10 \mathrm{~min}$. After being blocked by $10 \%$ normal donkey serum for $30 \mathrm{~min}$, cells were incubated at room temperature for $1 \mathrm{~h}$ with primary antibody diluted in antibody buffer $(50 \mathrm{mM}$ Tris- $\mathrm{HCl}, \mathrm{pH} 7.4$, $150 \mathrm{mM} \mathrm{NaCl}, 100 \mathrm{mM}$ L-Lysine, $1 \% \mathrm{BSA}$ and $0.04 \%$ azide). The following antibodies were used: A620 (1:1000), TuJ1 (Sigma-Aldrich; 1:1000), phosphoERK1/2 (Thr202/Tyr204) (Cell Signaling Technology, Danvers, MA, USA; 1:200). After incubation with the primary antibodies, they were rinsed and incubated for $1 \mathrm{~h}$ at room temperature with Alexa Fluor-labeled secondary antibodies (Molecular Probes, Leiden, The Netherlands; 1:800). After washing, the coverslips were mounted with glycerine/PBS containing $5 \mu \mathrm{g} / \mathrm{ml}$ Hoechst for nuclei staining. For active ERK staining, $50 \mathrm{mM} \mathrm{NaF}$ was added in antibody dilution buffer and wash buffer.

For living cell immunostaining, unfixed cultures were incubated with different antibodies 1E8 (1:100), A201 (1:500) and A620 (1:500) diluted in NB for 30 min at room temperature. ${ }^{3,15}$ After brief rinses, the cells were fixed in $4 \%$ PFA and blocked 
with $10 \%$ donkey serum, and then stained in secondary antibodies and Hoechst as described above.

The labeled cells were observed under fluorescence microscope (BX-61) or Olympus Confocal Microscope (FV1000).

RT-PCR. Total RNA from primary cortical neurons was isolated using Trizol reagent (Invitrogen) and was subsequently treated with RNase-free DNase I (Roche).

Synthesis of cDNA was performed by using BcaBest RNA PCR kit from TaKaRa according to the manufacturer's instructions. Specific primers and product size used for PCR were list in the Supplementary Table S1. $\beta$-Actin was chosen as the endogenous control in the assay. To ensure that the PCR products fell within the linear range, cycle dependence was carried out. The gel image was acquired in the Gel Doc 1000 system and analyzed using the Quantity One software (BioRad Laboratories, Hercules, CA, USA). Quantitative real-time PCR was performed using a Peltier Thermal Cycler (BioRad) plus Realtime PCR Master Mix (SYBR Green Toyobo, Osaka, Japan). Primers for real-time PCR of Nogo-A were: 5'-CTTTGGAACCTCAGACAGAA-3' (forward) and 5'-CTTTGGAACCTCAGACAGAA-3' (reverse)

Subcellular fractionation of cortical neurons. Subcellular fractionation was performed on cortical neurons using the ProteoExtract Subcellular Proteome Extraction kit (Calbiochem, Giessen, Germany) as per the manufacturer's instructions. This sequential extraction method relies on the different solubility of proteins in certain subcellular compartments to yield four fractions enriched in cytosolic (F1), membrane and membrane organelle-localized (F2), soluble and DNA-associated nuclear (F3) and cytoskeletal (F4) proteins. All samples were assayed for protein content by BCA protein assay kit (Pierce, Rockford, IL, USA) Equivalent amounts of proteins were resolved by SDS-PAGE, and western blotting was performed as described below.

Western blotting. The procedure of western blotting has been described previously. ${ }^{7}$ In brief, the total cell lysates or cerebral cortex extracts were prepared in high $\mathrm{KCl}$ lysis buffer (10 mM Tris- $\mathrm{HCl}, \mathrm{pH} 8.0,140 \mathrm{mM} \mathrm{NaCl}, 300 \mathrm{mM} \mathrm{KCl}, 1 \mathrm{mM}$ EDTA, $0.5 \%$ Triton $\mathrm{X}-100$ and $0.5 \%$ sodium deoxycholate) with complete protease inhibitor cocktail (Roche). The protein concentration was determined using BCA protein assay kit. The samples were separated by SDS-PAGE and transferred to polyvinylidene fluoride membranes (Roche). The membranes were treated with $1 \%$ blocking solution in TBS, followed by incubation with primary antibodies, and then POD-labeled secondary antibodies (Roche). The immunolabeled proteins were detected by BM Chemiluminescence Western Blotting kit (Roche). Densitometry quantification was acquired with Gel Doc 1000 system and analyzed using the Quantity One software. The primary antibodies were used as follows: A620 (1:25000), A201 (1:5000), A563 (1:1000) and phospho-AKT (S473) (Cell Signaling Technology; 1:1000); AKT (Cell Signaling Technology; 1:1000), phospho-ERK1/2 (Thr202/ Tyr204) (Cell Signaling Technology; 1:1000), ERK1/2 (Cell Signaling Technology; 1: 1000), Bcl-2 (Santa Cruz Technology, Santa Cruz, CA, USA; $1: 500)$, Prdx2-SO $_{3}$ (Abcam, Cambridge, UK; 1:2000), 2-Cys Prdx2 (Abcam; 1:1000), HA (Genomics, Shanghai, China; 1:5000), $\beta$-actin (AbMart, Shanghai, China; 1:1000).

For active AKT and ERK1/2 detection, $50 \mathrm{mM} \mathrm{NaF}$ was included in the antibody dilution buffer and wash buffer

In situ GST pull-down assay. Rho GTPases activity was measured as described, ${ }^{15}$ cell cultures were washed in freshly prepared $\mathrm{TBS} / \mathrm{NaF}$ and immediately fixed with 4\% PFA and cold methanol. Then, cells were incubated with $10 \mu \mathrm{g} / \mathrm{ml}$ GST-RBD or GST-PBD overnight at $4{ }^{\circ} \mathrm{C}$, and later washed three times in TBS/NaF and blocked in 10\% donkey serum. Anti-GST antibody $(1: 2000)$ and Alexa Fluor 488 goat anti-mouse IgG (Molecular Probes; $1: 800$ ) were used to visualize active Rho GTPases. To quantify the densitometry, microphotographs obtained in fluorescence microscope were analyzed with IPP6.0.

GST pull-down assay. Following previous method, ${ }^{40}$ GST and GST-AM immobilized on glutathione agarose beads were incubated with TAT-HA-Prdx2 at $4{ }^{\circ} \mathrm{C}$ for $2 \mathrm{~h}$ in PBS containing $0.1 \%$ Triton $\mathrm{X}-100$ with constant rocking. The beads were washed three times with PBS, and bound proteins were resolved by SDS-PAGE and processed for western blotting using anti-HA antibody.

Conversely, GFP-M1 was overexpressed in 293FT cell line, and after $48 \mathrm{~h}$ transfection, cells were lysed with $0.1 \%$ NP40 extract buffer, and then cell lysates were incubated with GST- or GST-Prdx2-coupled glutathione agarose beads for $7 \mathrm{~h}$ at $4{ }^{\circ} \mathrm{C}$ with constant rocking, respectively. The beads were washed three times with $0.1 \%$ NP40 wash buffer, and bound proteins were resolved by SDS-PAGE and processed for western blotting using anti-GFP antibody.

Pull-down assays with His-tagged proteins. As previous study described, cortical neurons $\left(1.5 \times 10^{7}\right.$ cells per plate) treated with $0.2 \mu \mathrm{M}$ TAT-GFP and TAT-AM were lysed in 0.1\% NP40 extract buffer, and then cell lysates were incubated with Ni-NTA resin beads at $4{ }^{\circ} \mathrm{C}$ for $2 \mathrm{~h}$ with constant rocking. The beads were washed three times with $0.1 \%$ NP40 wash buffer, and bound proteins were resolved by SDS-PAGE and processed for immunoblotting with antiPrdx2-SO3 antibody.

RNA interference. According to the targeting sequences of rat Nogo-A, two pairs of shRNA and one siRNA was synthesized. Oligonucleotides encoding shRNAs were cloned into the pSuper vector to generate pSuper-Nogo-A (against Nogo-A) and pSuper-panNogo (against Nogo-A/B/C). The target sequences are shown as following: pSuper-Nogo-A, 5' -GAGGATTTCCCATCTGTCCT-3'; pSuperpanNogo, 5'-TTTGCAGTGTTGATGTGG-3'; and Nogo-A-siRNA, 5'-GTTTGCAGT GTTGATGTGG-3'. The efficacy of knocking down endogenous Nogo-A was confirmed in rat PC12 cell lines and cortical neurons. The targeting sequence of Prdx2-siRNA was 5'-TCCAGGCCTTTCAGTATAC-3', and the knockdown efficacy was examined in neurons.

Site-directed mutagenesis of Cys residues in the Nogo-Aspecific region. Cys was replaced by Ala with QuikChange Lightning MultiSite-Directed Mutagenesis Kit (Stratagene, La Jolla, CA, USA) using expression construct TAT-M1 as a template. All mutagenesis sequences were confirmed by DNA sequencing. Among them, TAT-M1-3CA (mutations at 424464 and 559) and TAT-M1-2CA (mutations at 424 and 464) were selected in the Cys mutation experiment. TAT-M9-3CA was constructed through inserting M9-3CA PCR product from TAT-M1-3CA to PTAT-HA vector

Selective alkylation of protein Cys residues by BIAM at pH 6.5. This experiment is based on the fact that $\mathrm{H}_{2} \mathrm{O}_{2}$ and BIAM (Biotium, Hayward, CA, USA) selectively and competitively react with Cys residues that exhibit a low pKa. ${ }^{28}$ TAT-M9-WT or TAT-M9-3CA $(1 \mu \mathrm{g})$ in $100 \mu \mathrm{l}$ of $25 \mathrm{mM}$ Hepes- $\mathrm{NaOH}$ (pH 7.0) was incubated for $10 \mathrm{~min}$ at room temperature in the absence or presence of $1 \mathrm{mM} \mathrm{H}_{2} \mathrm{O}_{2}$. The oxidation reaction was terminated by $0.1 \mathrm{mg} / \mathrm{ml}$ catalase and adjustment of $\mathrm{pH}$ to 6.5 with $0.2 \mathrm{M}$ acetic acid, and then BIAM was added to a final concentration of $40 \mathrm{mM}$. After incubation in dark for $15 \mathrm{~min}$ at room temperature, the labeling reaction was terminated by $20 \mathrm{mM} \beta$-mercaptoethanol and adjustment of $\mathrm{pH}$ to 8.5 with $1 \mathrm{M}$ Tris base. Then, $15 \mu \mathrm{l}$ of each reaction mixture was subjected to SDS-PAGE and blotted with HRP-conjugated streptavidin (Pierce).

Statistical analysis. The data shown in this study were expressed as mean \pm S.D. Statistical significance was evaluated by one-way ANOVA or paired $t$-test, and probability values of $<5 \%$ were considered significant.

\section{Conflict of Interest}

The authors declare no conflict of interest

Acknowledgements. We thank $\mathrm{Dr}$. Dowdy $\mathrm{S}$ for generously providing us pTAT-HA vector, Dr. Olson MF for TAT-C3 expression vector, Dr. Xiong WC for GST-RBD and GST-PBD plasmids and Dr. Sockanathan S for HA-Prdx2 construct. We are grateful for the donation of the human KIAA0866 clone from the Kazusa DNA Research Institute (Chiba, Japan). This work was supported by National Natural Science Foundation of China (Nos. 30770671 and 30970936) and Shanghai Leading Academic Discipline Project (No. B205). We apologize to the investigators whose work we could not cite owing to space restrictions.

1. He Z, Koprivica V. The Nogo signaling pathway for regeneration block. Annu Rev Neurosci 2004; 27: 341-368.

2. Schwab ME. Functions of Nogo proteins and their receptors in the nervous system. Nat Rev Neurosci 2010; 11: 799-811.

3. Oertle T, van der Haar ME, Bandtlow CE, Robeva A, Burfeind P, Buss A et al. Nogo-A inhibits neurite outgrowth and cell spreading with three discrete regions. J Neurosci 2003; 23: 5393-5406. 
4. Hu F, Strittmatter SM. The N-terminal domain of Nogo-A inhibits cell adhesion and axonal outgrowth by an integrin-specific mechanism. J Neurosci 2008; 28: 1262-1269.

5. Joset A, Dodd DA, Halegoua S, Schwab ME. Pincher-generated Nogo-A endosomes mediate growth cone collapse and retrograde signaling. J Cell Biol 2010; 188: 271-285.

6. Hunt D, Coffin RS, Prinjha RK, Campbell G, Anderson PN. Nogo-A expression in the intact and injured nervous system. Mol Cell Neurosci 2003; 24: 1083-1102.

7. Jin WL, Liu YY, Liu HL, Yang $H$, Wang $Y$, Jiao $X Y$ et al. Intraneuronal localization of Nogo-A in the rat. J Comp Neurol 2003; 458: 1-10.

8. Mingorance-Le Meur A, Zheng B, Soriano E, del Rio JA. Involvement of the myelinassociated inhibitor Nogo-A in early cortical development and neuronal maturation. Cereb Cortex 2007; 17: 2375-2386.

9. Petrinovic MM, Duncan CS, Bourikas D, Weinman O, Montani L, Schroeter A et al. Neuronal Nogo-A regulates neurite fasciculation, branching and extension in the developing nervous system. Development 2010; 137: 2539-2550.

10. Delekate A, Zagrebelsky M, Kramer S, Schwab ME, Korte M. NogoA restricts synaptic plasticity in the adult hippocampus on a fast time scale. Proc Natl Acad Sci USA 2011; 108 2569-2574.

11. Zagrebelsky M, Schweigreiter R, Bandtlow CE, Schwab ME, Korte M. Nogo-A stabilizes the architecture of hippocampal neurons. J Neurosci 2010; 30: 13220-13234.

12. Teng FY, Tang BL. Nogo signaling and non-physical injury-induced nervous system pathology. J Neurosci Res 2005; 79: 273-278.

13. Yan $R$, Shi $Q, H u X$, Zhou X. Reticulon proteins: emerging players in neurodegenerative diseases. Cell Mol Life Sci 2006; 63: 877-889.

14. Barnham KJ, Masters CL, Bush Al. Neurodegenerative diseases and oxidative stress. Nat Rev Drug Discov 2004; 3: 205-214.

15. Zhao XH, Jin WL, Ju G. An in vitro study on the involvement of LINGO-1 and Rho GTPases in Nogo-A regulated differentiation of oligodendrocyte precursor cells. Mol Cell Neurosci 2007; 36: 260-269

16. Sugo $\mathrm{N}$, Oshiro $\mathrm{H}$, Takemura $\mathrm{M}$, Kobayashi $\mathrm{T}$, Kohno $\mathrm{Y}$, Uesaka $\mathrm{N}$ et al. Nucleocytoplasmic translocation of HDAC9 regulates gene expression and dendritic growth in developing cortical neurons. Eur J Neurosci 2010; 31: 1521-1532.

17. Dubreuil $\mathrm{Cl}$, Winton MJ, McKerracher L. Rho activation patterns after spinal cord injury and the role of activated Rho in apoptosis in the central nervous system. J Cell Biol 2003; 162 233-243.

18. Inoue H, Lin L, Lee X, Shao Z, Mendes S, Snodgrass-Belt P et al. Inhibition of the leucinerich repeat protein LINGO-1 enhances survival, structure, and function of dopaminergic neurons in Parkinson's disease models. Proc Natl Acad Sci USA 2007; 104: 14430-14435.

19. Dupuis L, Pehar M, Cassina P, Rene F, Castellanos R, Rouaux C et al. Nogo receptor antagonizes p75NTR-dependent motor neuron death. Proc Natl Acad Sci USA 2008; 105 740-745.

20. Wang $Q$, Gou X, Xiong L, Jin W, Chen S, Hou L et al. Trans-activator of transcriptionmediated delivery of NEP1-40 protein into brain has a neuroprotective effect against foca cerebral ischemic injury via inhibition of neuronal apoptosis. Anesthesiology 2008; 108: 1071-1080.

21. Diebold BA, Fowler B, Lu J, Dinauer MC, Bokoch GM. Antagonistic cross-talk between Rac and Cdc42 GTPases regulates generation of reactive oxygen species. J Biol Chem 2004; 279: 28136-28142.

22. Zander H, Hettich $E$, Greiff K, Chatwell L, Skerra A. Biochemical characterization of the recombinant human Nogo-A ectodomain. FEBS J 2007; 274: 2603-2613.
23. Ueda S, Masutani H, Nakamura H, Tanaka T, Ueno M, Yodoi J. Redox control of cell death. Antioxid Redox Signal 2002; 4: 405-414.

24. Subramaniam S, Unsicker K. ERK and cell death: ERK1/2 in neuronal death. FEBS J 2010 277: 22-29.

25. Aleyasin H, Rousseaux MW, Marcogliese PC, Hewitt SJ, Irrcher I, Joselin AP et al. DJ-1 protects the nigrostriatal axis from the neurotoxin MPTP by modulation of the AKT pathway. Proc Natl Acad Sci USA 2010; 107: 3186-3191.

26. Krishna S, Low IC, Pervaiz S. Regulation of mitochondrial metabolism: yet another facet in the biology of the oncoprotein Bcl-2. Biochem J 2011; 435: 545-551.

27. Wood ZA, Schroder E, Robin Harris J, Poole LB. Structure, mechanism and regulation of peroxiredoxins. Trends Biochem Sci 2003; 28: 32-40.

28. Kim JR, Yoon HW, Kwon KS, Lee SR, Rhee SG. Identification of proteins containing cysteine residues that are sensitive to oxidation by hydrogen peroxide at neutral $\mathrm{pH}$. Anal Biochem 2000; 283: 214-221.

29. Simonen M, Pedersen V, Weinmann O, Schnell L, Buss A, Ledermann B et al. Systemic deletion of the myelin-associated outgrowth inhibitor Nogo-A improves regenerative and plastic responses after spinal cord injury. Neuron 2003; 38: 201-211.

30. Yang YS, Harel NY, Strittmatter SM. Reticulon-4A (Nogo-A) redistributes protein disulfide isomerase to protect mice from SOD1-dependent amyotrophic lateral sclerosis J Neurosci 2009; 29: 13850-13859.

31. Kilic E, ElAli A, Kilic U, Guo Z, Ugur M, Uslu U et al. Role of Nogo-A in neuronal survival in the reperfused ischemic brain. J Cereb Blood Flow Metab 2010; 30 969-984.

32. Woolf CJ. No Nogo: now where to go? Neuron 2003; 38: 153-156.

33. Weinmann O, Schnell L, Ghosh A, Montani L, Wiessner C, Wannier T et al. Intrathecally infused antibodies against Nogo-A penetrate the CNS and downregulate the endogenous neurite growth inhibitor Nogo-A. Mol Cell Neurosci 2006; 32: 161-173.

34. Yao Q, Jin WL, Wang Y, Ju G. Regulated shuttling of Slit-Robo-GTPase activating proteins between nucleus and cytoplasm during brain development. Cell Mol Neurobiol 2008; 28: 205-221.

35. Murphy TH, Baraban JM. Glutamate toxicity in immature cortical neurons precedes development of glutamate receptor currents. Brain Res Dev Brain Res 1990; 57: $146-150$

36. Siman R, Flood DG, Thinakaran G, Neumar RW. Endoplasmic reticulum stress-induced cysteine protease activation in cortical neurons: effect of an Alzheimer's disease-linked presenilin-1 knock-in mutation. J Biol Chem 2001; 276: 44736-44743.

37. Zhao XH, Jin WL, Wu J, Mi S, Ju G. Inactivation of glycogen synthase kinase-3beta and upregulation of LINGO-1 are involved in LINGO-1 antagonist regulated survival of cerebellar granular neurons. Cell Mol Neurobiol 2008; 28: 727-735.

38. Xiao N, Callaway CW, Lipinski CA, Hicks SD, DeFranco DB. Geldanamycin provides posttreatment protection against glutamate-induced oxidative toxicity in a mouse hippocampal cell line. J Neurochem 1999; 72: 95-101.

39. Fan J, Cai H, Yang S, Yan L, Tan W. Comparison between the effects of normoxia and hypoxia on antioxidant enzymes and glutathione redox state in ex vivo culture of CD34(+) cells. Comp Biochem Physiol B 2008; 151: 153-158.

40. Liu B, Lee HY, Weinzimer SA, Powell DR, Clifford JL, Kurie JM et al. Direct functional interactions between insulin-like growth factor-binding protein-3 and retinoid $X$ receptor-alpha regulate transcriptional signaling and apoptosis. J Biol Chem 2000; 275: 33607-33613.

\section{Supplementary Information accompanies the paper on Cell Death and Differentiation website (http://www.nature.com/cdd)}

